\title{
PHENOMENOLOGY IN A WETSUIT: UNDERSTANDING BIOPHILIA IN \\ PACIFIC COASTAL ENVIRONMENTS
}

By

\author{
MEG ELISE BANAVAGE
}

B.A.(Hons), Dalhousie University, 2008

A thesis submitted in partial fulfillment of the requirements for the degree of

\author{
MASTER OF ARTS \\ in \\ ENVIRONMENTAL EDUCATION AND COMMUNICATION \\ We accept this thesis as conforming \\ to the required standard
}

Dr. Nevin J. Harper, Outward Bound Canada

Thesis Supervisor

Dr. Richard Kool, Thesis Committee Member

School of Environment and Sustainability

Michael-Anne Noble, Director

School of Environment and Sustainability

ROYAL ROADS UNIVERSITY

December 2012

(C) Meg Elise Banavage, 2012 


\begin{abstract}
To examine possible links between biophilia (love for living systems) and outdoor adventure training, this study explored various emotional relationships participants developed during Hooksum Outdoor School on Vancouver Island, British Columbia. Drawing from phenomenological psychology, ecopsychology, outdoor adventure training, and biophilia literature, I sought to answer the questions (1) if, and how, individuals develop emotional relationships with coastal environments; (2) what role the ocean plays in emotional change; (3) how individuals act in response to their relationships with the coast. Analysis included grouping themes from observation notes, questionnaires, and Interpretative Phenomenological Analysis of individual interviews. A focus was bringing the researcher into participants' lifeworlds as they experienced the program. Four individual participant stories demonstrate active relationshipbuilding (1) within participants' inner selves; (2) between each other; (3) with the coastal environment. Findings contribute to recommendations for future research, providing insight into how program design can effectively address the biophilia tendency.
\end{abstract}




\section{Table of Contents}

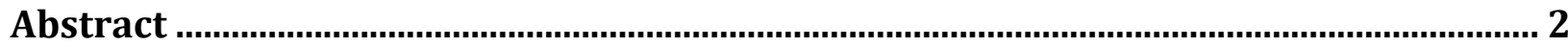

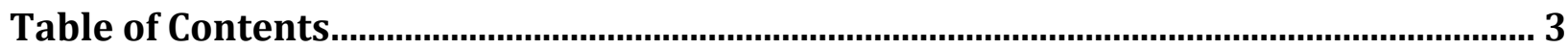

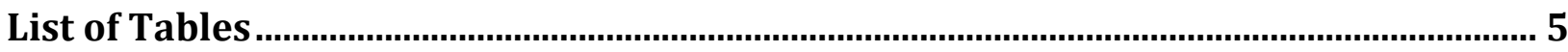

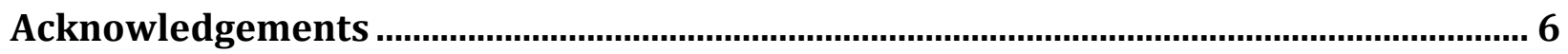

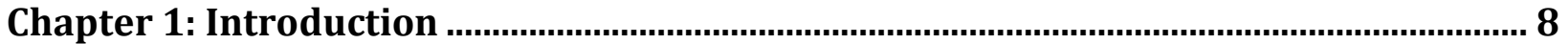

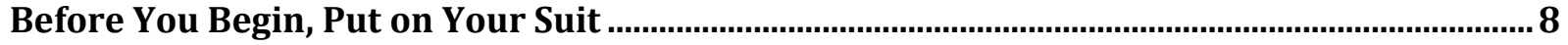

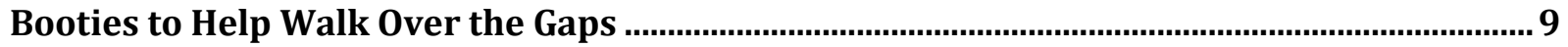

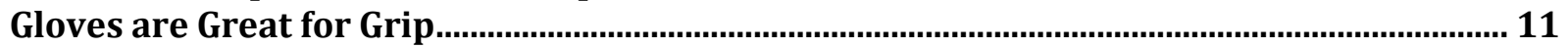

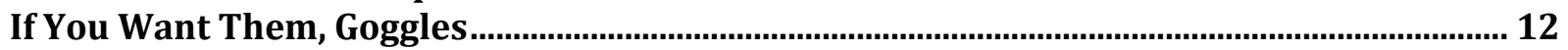

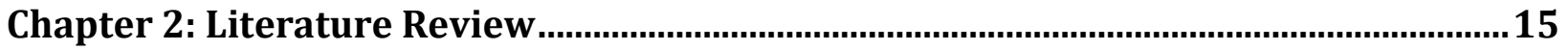

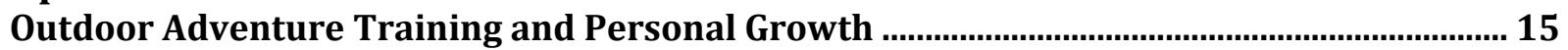

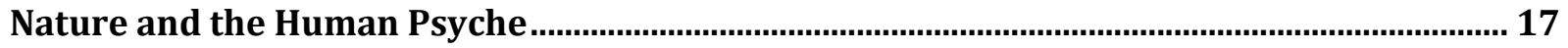

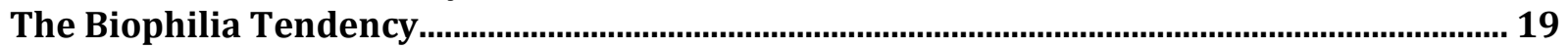

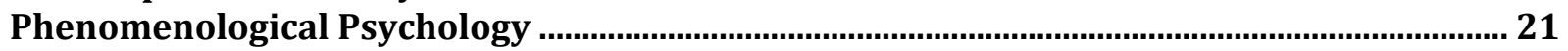

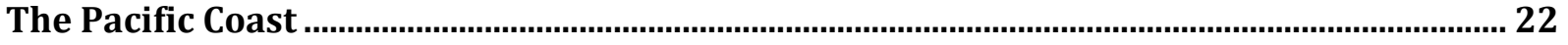

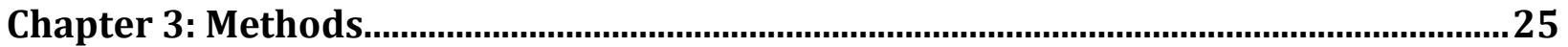

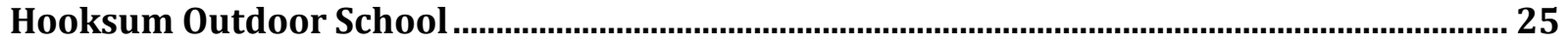

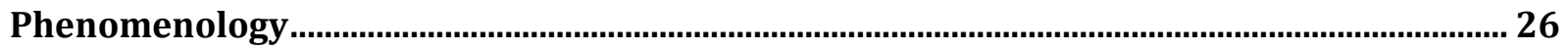

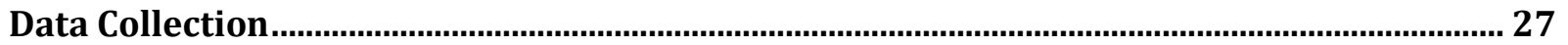

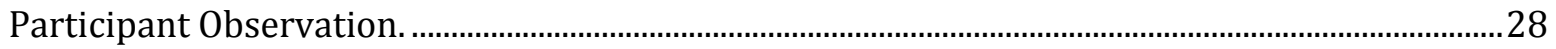

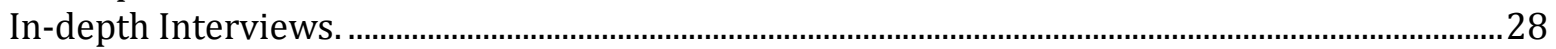

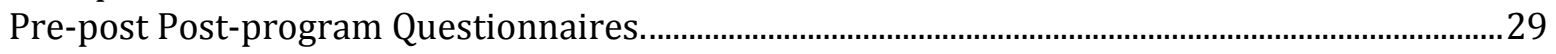

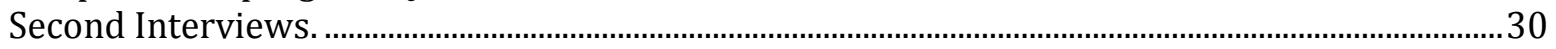

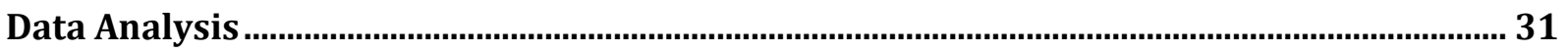

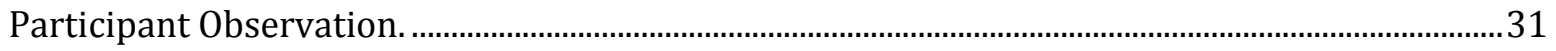

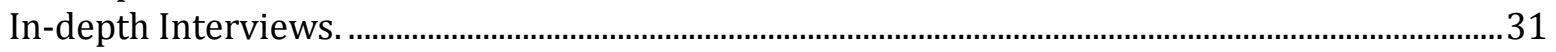

Pre-post Post-program Questionnaires and Second Interviews......................................................32

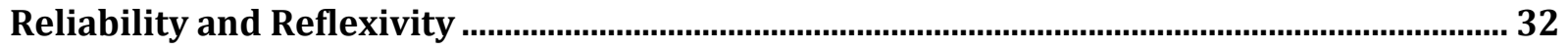

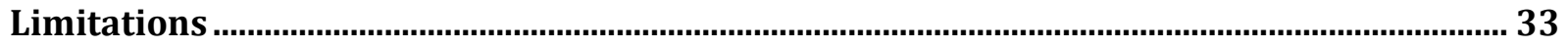

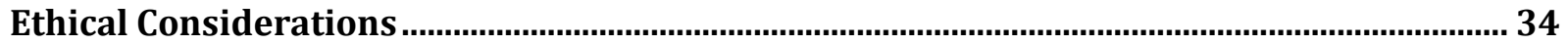

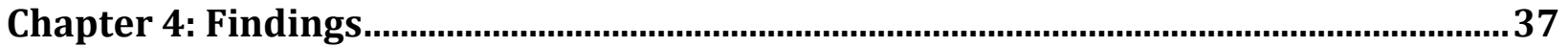

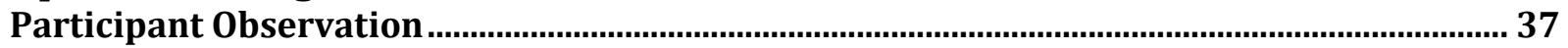

Theme 1: Expressing feelings of awe and serenity in nature's beauty............................................... 37

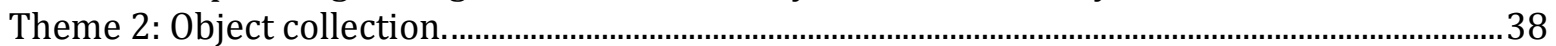

Theme 3: Familial atmosphere and closeness between group members............................................39

Theme 4: Energy boosts when in or on the water. …................................................................................ 40

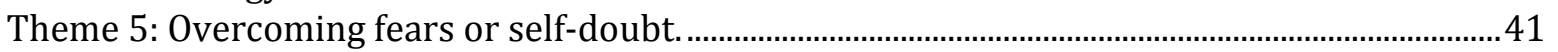

Pre-post Post-program Questionnaires and Second Interviews ................................................ 42

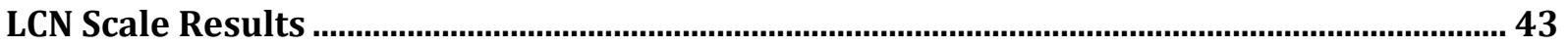

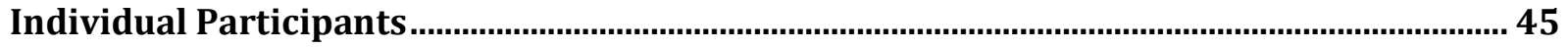

Alex.

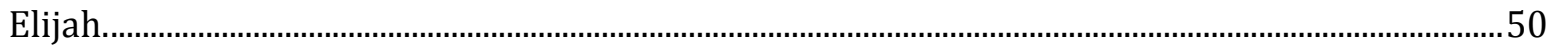

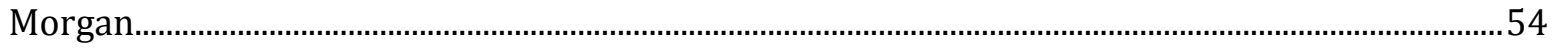




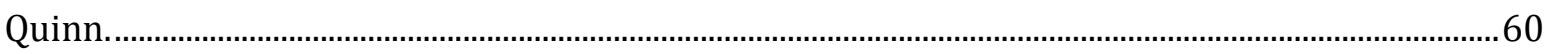

Chapter 5: Discussion ..............................................................................................................6 68

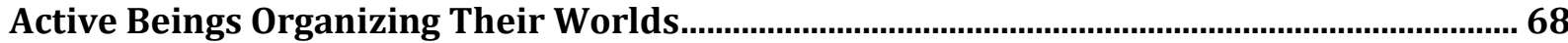

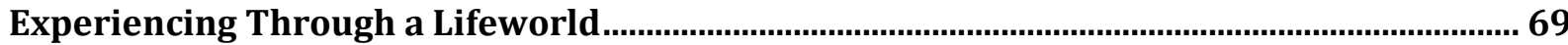

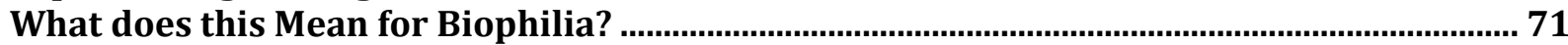

Humanistic Biophilia and Attachment for Environments......................................................... 72

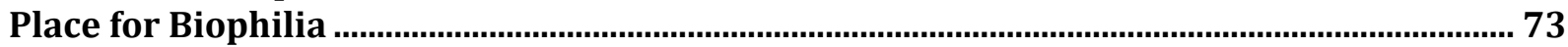

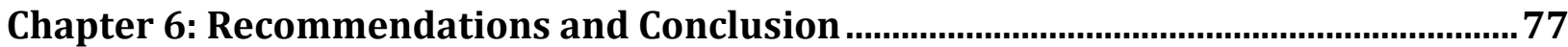

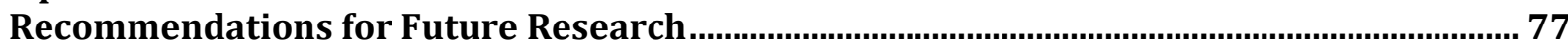

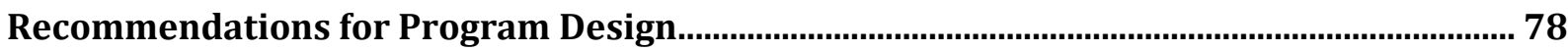

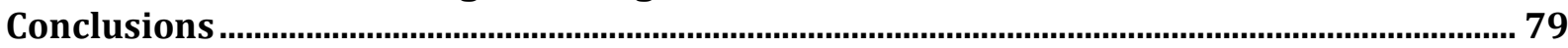

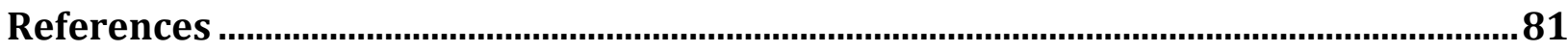

Appendix A: Letter of Invitation to Participate in Research ............................................86

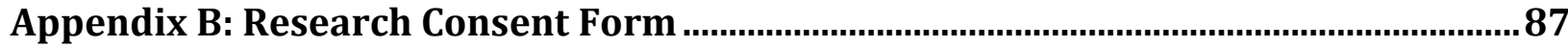

Appendix C: Semi-Structured, In-Depth Interview Questions..........................................89

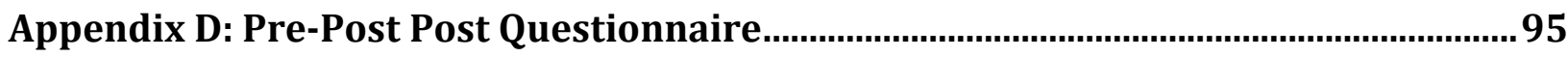

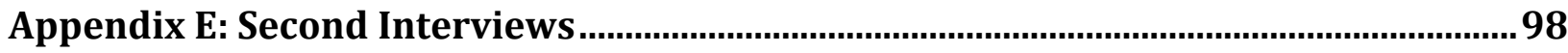

Appendix F: Item Response Distributions of Participant Love and Care for Nature

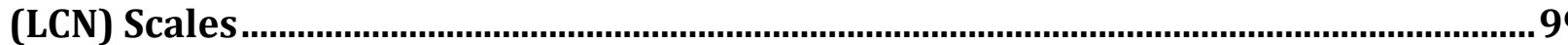




\section{List of Tables}

Table 1: Kellert's (1993) Nine Dimensions of the Biophilia Tendency ...................................... 20

Table 2. Emergent Themes from Four Participant Pre-post Post-program Questionnaires ......... 42

Table 2: Emergent Themes from Four Participant Second Interviews ....................................... 43

Table 3: Item Response Distributions for Participant Love and Care for Nature (LCN) Scales.. 44 


\section{Acknowledgements}

Dr. Nevin J. Harper, Outward Bound Canada

Dr. Rick Kool, Royal Roads University

Hooksum Outdoor School

My Loved Ones

Royal Roads University

Birgit and Robert Bateman Bursary

TD Bursary

TD Environmental Sustainability Scholarship

Social Sciences and Humanities Research Council

Joseph-Armand Bombardier Canada Graduate Scholarship

Tarn 2, my tent

Thank you. 
The sun was beating down over the clear blue of the Pacific; the waves breaking left and crashing against the black rocky reef. I was out on the water with a local woman who was teaching me how to read the ocean as her husband swam with their two young kids in a nearby tidal pool. Pohoiki, a word meaning small depression, was a place with a mind of its own. With my friend's help, I was learning the ocean's language: the singing of her break, the firm lessons of her rocky shore, her mischievous giggle as she receded back out to the open water. 'She will be kind to you, but she will always let you know that she is in charge'.

I lay on the board and began to paddle as I was told, 'Here it comes!' I could feel the water begin to rush faster underneath me, behind me; I was pushed forward with wind and salt. Then it came. That feeling, for which there are no words, it just says 'now'. I pushed up, slid my feet in between my hands, and stood. Nothing else mattered. And it all made sense. 


\section{Chapter 1: Introduction}

\section{Before You Begin, Put on Your Suit}

As an individual who enjoys engaging with the ocean, I recognize that the core of who I am is covered in a layer of assumptions. By recognizing that I am wearing a suit of beliefs and experiences, I can then begin to critically look at how humans develop relationship with the ocean, and what might be, in others, the same as or different from my beliefs.

I believe that loving relationships from which we learn, are challenged by, and passionately nurture, can develop between humans and the natural environment, particularly the ocean. Through personal experience and friendly conversation, I have begun to realize that an emotional experience or process is activated when we engage with the ocean through kayaking, surfing, and other forms of ocean-based sport. I have also noticed that this dimension seems to be nurtured when combined with outdoor adventure training. Outdoor adventure programs define what they do as putting people "in challenging, adventurous outdoor situations" (Outward Bound International, 2004, n.p.). Outdoor adventure training is reflected in many outdoor programs that provide "a solid foundation of outdoor and leadership skills and competencies" (Hooksum Outdoor School, 2011, n.p.) and participation in outdoor activities (TREK, 2011). The existence of programs that combine outdoor adventure training with a lived experience (living on-site for 3-4 weeks or more) drives my curiosity as to whether or not I am alone in my observations and queries. What is this emotional process and why is it activated during outdoor adventure training?

Many outdoor adventure programs on British Columbia's coast promote technical skills and certifications. Some advertise emotional benefits for an individual participating in outdoor adventure: confidence, self-acceptance, or therapeutic-related terminology. I do not refute the importance of these benefits. I do, however, notice that it is rare to discover a program that lists 
the process of developing cognitive and emotional relationships, loving relationships, with the natural environment as beneficial on its website. The ideas surrounding emotional relationshipbuilding with nature are difficult to demonstrate and virtually nonexistent in research. Many perspectives within research, cultural groups, and adherents to particular spiritual beliefs, will claim that having a relationship with the earth is a good thing; it is when trying to understand how that relationship is cultivated that things become tricky. Based on my own personal experience as an outdoor enthusiast and educator, I believe coastal outdoor adventure training facilitates emotional relationship-building with the ocean, and I was driven to search for biophilia (love for life and living systems) (Kellert, 1993; Soulé, 1993; Wilson, 1993) within the lived experiences of those who undergo outdoor adventure training. This study uses the terms outdoor adventure training and adventure education interchangeably. Hattie, Marsh, Neill, and Richards (1997) define adventure education as "doing physically active things away from the person's natural environment" (p. 44) and include elements such as wilderness settings, challenging tasks, small groups, and lasting 2 to 4 weeks.

My interest in the ocean began as a young girl on a family vacation to Prince Edward Island. It was there that I saw the pure strength and freedom of water. My curiosity about the emotional experience I continuously feel with the ocean was deepened by summer camp outtrips, learning to surf, living in Costa Rica, Halifax, Hawai'i and British Columbia. Academic literature involving ecopsychology and biophilia refined my research focus. I became intrigued and decided to explore if, and how, humans experience a biophilic relationship with coastal environments. Is what occurs emotionally more than a positive feeling? Am I alone in this relationship-building? If others feel the same, then what process is going on within us?

\section{Booties to Help Walk Over the Gaps}

My curiosity presented an opportunity to conduct a phenomenological exploration into 
ecopsychology and adventure education fields. Researchers have noted that the human search for fulfillment in life is deeply tied with relationships we have with nature (Kellert, 1993).

Academics and writers have also begun to promote the need to connect to nature, spend time outdoors, and to foster a sense of place with one's environment (Louv, 2005; Orr, 2004; Sobel, 1998). However, I have found little research that explains what occurs on a cognitive and emotional level when experiencing a feeling of love in natural environments. In addition, there seems to be a lack of connection between outdoor adventure training and relationship-building with nature. These are gaps in both research and practice, as outdoor adventure training is a field that uses "the challenges of wilderness living (...) the aesthetic beauty of natural environments" (Martin, Cashel, Wagstaff \& Breunig, 2006, p. 9) and can, in my view, connect training with emotional, human-nature relationship-building. With a specific focus on Pacific coastal environments, my research seeks to take the phrase "I love the ocean", commonly heard in British Columbia, and question if these are empty words or a result of an inner process that deepens ones love of living systems in the environment.

Researchers including Kellert (1993) have used the term biophilia tendency to describe how one expresses biophilia, which is a notion that suggests, "individual identity and personal fulfillment somehow depend on our relationship to nature" (p. 42). I think this dependency, along with other psychological and emotional processes, can be heightened during outdoor adventure training. From my own experience leading out-trips with youth, I have come to believe that what individuals learn in outdoor adventure training can affect other emotional aspects of their lives. For example, overcoming a challenge in the natural environment can give people confidence and skills to overcome hardships in other areas of their lives. From setting up tarps in a team to cooking for each other, outdoor education provides a way to promote social skills and interaction. Outdoor adventure training can also cultivate a unique understanding for nature. 
Paddling through rapids can expose one to the strength and power of water. Portaging a canoe uphill in the mud can give one self-esteem and appreciation for the natural downhill slopes of majestic mountains. If outdoor adventure training can affect our emotions in multiple ways, it is possible that a biophilia tendency could also be activated through these activities.

In addition to outdoor adventure training literature, the ideas surrounding biophilia also emerge in social sciences and conservation research. Perkins (2010) notes, "the emotions of love, awe, wonder, and deep reverence for nature (...) have received scant attention from psychological researchers" (p. 456). This gap in research must be addressed. What's more, within the research that recognizes biophilia, there are few studies that explore how this tendency develops or is nurtured. Both Orr (2004) and Sobel (1998) illuminate the idea that humans will only save what they love; therefore, I think it stands to reason that we must nurture this love.

Thinking about love as an element in science and education overlooked, Orr (2011a) claimed, and this creates a struggle in motivating others to engage in a field they are passionate about, whether it is conservation biology or other disciplines. Emotions should not be overlooked in biological and education research when they help make up the core of human beings; they should be acknowledged, validated, and understood. Understanding how emotional relationships develop becomes a responsible way to bridge gaps in research between outdoor adventure training literature, biophilia research, and conservation studies. As ecological, psychological, and outdoor education researchers, we need to be looking at love and the emotions that motivate people to develop relationships and act to protect them.

\section{Gloves are Great for Grip}

The above literature notes that individuals need to love something in order to save it, and while it is useful, more is needed to move forward. The reader is left feeling, 'alright, now what? If we only save what we love, how do we cultivate a love for nature?' Ecopsychology research 
illustrates the cognitive and emotional relationships humans can have with their environment. Albrecht et al. (2007) discovered that when people hear their home environment is being threatened or destroyed, they experience pangs of homesickness. We often attribute homesickness with being away from those we love, and as research has demonstrated a personal attachment for our home environments (Albrecht et al., 2007; Kellert, 1993; Orr, 2004; Sobel, 1998; Wilson, 1993), I believe the same emotional process associated with being near a loved one can occur in relationships with nature. In order to investigate the possibility of developing this loving relationship, I am interested in exploring what occurs in relation to an individual's biophilia tendency throughout the lived experience of participants attending Hooksum Outdoor School, a 28 day program on the west coast of Vancouver Island filled with leadership training, outdoor skills such as remote surfing, coastal hiking and leadership, in addition to certifications in wilderness first aid and kayaking.

My research question was, "What is the relationship between outdoor adventure training and a biophilia tendency in participants learning and living in Pacific coastal environments?" Other questions that guided my research were (a) how do participants develop emotional relationships with their environment; (b) what role does the ocean play in emotional change; (c) how do participants act on their relationships with the coast?

\section{If You Want Them, Goggles}

Here is an outline to help see what lies ahead in this thesis. First I review the literature, theories, and concepts regarding outdoor adventure training, ecopsychology, biophilia, and phenomenological psychology. These disciplines provided theoretical framework for my research. My research methodology is presented, followed by both quantitative and qualitative findings. Discussion and recommendations for future research and program design are also included. 
Understanding a biophilia tendency during outdoor adventure training can at times feel like being caught in an undertow. Experiences are subjective, and emotional change is difficult to measure and discuss. Yet people state that they love the ocean without a second thought, and in my experience, those who participate in outdoor adventure training tend to say it often. What I feel is needed is an exploration into what occurs within individuals as they actively engage with the coast. It is not my aim to discover standard assumptions about the biophilia tendency and outdoor adventure training, although the findings do suggest common themes and may spark interest in research. This thesis shares the stories of participants at Hooksum Outdoor School, their experiences with the Pacific Ocean, and what coastal environments mean to them. 
"Even in the months of May as a child, I would force myself, me and my cousins would force ourselves, to go take a dip in the ocean. Even if it was only for three minutes. It was soothing." 


\section{Chapter 2: Literature Review}

In this chapter the literature pertaining to outdoor adventure training, ecopsychology, biophilia, and phenomenological psychology is explored. First, there is a summary of arguments that have claimed direct experience and outdoor education facilitate personal growth and valuing of nature within individuals. Second, ecopsychology research will be presented, specifically assertions that the human psyche is connected to changing environmental conditions, whether being compromised in times of environmental distress or restored in thriving ecosystems. Third, I will explore theories surrounding the biophilia tendency, and the research supporting claims that humans are able to experience emotional relationships with the natural environment. Fourth, I will explore phenomenological psychology and give examples of cases that have used this research method to better understand a person's experience in nature. Last, I give an explanation of how this thesis fits into the research presented.

\section{Outdoor Adventure Training and Personal Growth}

Researchers like Smith and Williams (1999, as cited in Martin et al., 2006) explain that outdoor adventure education is rooted in experiential education, a form of education that can cultivate a personal affinity with nature based on direct experience. This stems from the view that experience contributes to understanding of the environment. Direct experience has also been promoted throughout both education and psychology research due to multiple acclaimed benefits for the individual. For example, the outdoor TREK program in British Columbia was designed specifically:

on the belief that outdoor adventure and experiential education, combined with academic work and a bioregional overview, will allow students to develop their skills, confidence and leadership, connect them to the landscape they live in, and educate them about what they can do to move towards living sustainably. (Blaikie, 2008, p. 20) 
The field of outdoor adventure training generates benefits for individual skill development, a chance for personal and interpersonal growth, self-confidence, and healthy lifestyles (Martin et al., 2006, p. 9). Outward Bound Canada (2012) describes their adventure programs as a chance for individuals to meet and overcome challenges, develop technical skills that contribute to wilderness living, and foster character attitudes that are necessary for group living and teamwork. Direct experience is the foundation of this pedagogy.

In addition to technical skills, researchers have shown direct experience and outdoor education to be linked with positive environmental attitudes and values (Martin et al., 2006; Orr, 2011b, Rowley, 2010; Sobel, 1998). Orr (2011b) notes that experience in the natural world is necessary for understanding the environment; by experiencing what it is like to live in nature, one can recognize the difference between a healthy environment and an unhealthy one. He has stated:

[s]tudents taught environmental awareness in a setting that does not alter their relationship to basic life-support systems learn that it is sufficient to intellectualize, emote, or posture about such things without having to live differently. Environmental education ought to change the way people live, not just how they talk. (Orr, 2011b, p. 257)

Other researchers like Sobel (1998) have argued that positive environmental ethics and values are connected to outdoor education. Sobel demonstrated the pivotal link between opportunities for children to be outside and the development of positive environmental attitudes; he asserted that this opportunity to directly bond with nature is a pre-requisite for encouraging environmental action.

It is clear that the use of technical skill development for personal growth, and the connection to environmental attitudes and values, gives outdoor adventure training an important 
niche in environmental education and psychology. It helps in understanding the link between action and feeling.

\section{Nature and the Human Psyche}

In addition to the outdoor adventure literature outlined above, many researchers have argued that our emotional and psychological dimensions are linked with our surrounding environment, either negatively or positively (Abram, 2005; Albrecht et al., 2007; Kellert, 1993; Kidner, 2007; Orr, 2004; Randall, 2009; Sobel, 1998). Merriam-Webster's online medical dictionary defines psyche as the mind, including both conscious and unconscious elements; their basic dictionary also uses the definitions of soul, personality or mind (Merriam-Webster, 2012). Derived from a word with Greek origins in soul or life, numerous researchers and writers see the relationship between a healthy life- cognitive, emotional, physical, or spiritual- and ecological health (Abram, 2005; Albrecht et al., 2007; Louv, 2005; Kellert, 1993; Kidner, 2007; Randall, 2009; Orr, 2004; Sobel, 1998). Whether for health and developmental benefits (Louv, 2005), therapeutic practice (Smith, 2010), or to cultivate a generation of environmentally aware and empowered children (Sobel, 1998), there is an understanding that being outdoors triggers a response from our inner selves.

Neill (2008) reviews outdoor education and psychological literature, and notes that overcoming hardship in natural areas can offer a context for psychological restoration when individuals apply the character attributes used to recover from these difficult times to their own personal struggles. There are many physical, emotional, and cognitive benefits of being outdoors that are widely recognized by the general public: exercise, relaxation, and mental clarity, among others. One specific body of research is Attention Restoration Theory (ART). ART explains how attentional fatigue is restored and the role natural settings play in this process (Kaplan, 1995). Supporters of ART have claimed that having contact with nature can support attentional 
functioning (Taylor, Kuo \& Sullivan, 2001). Smith (2010) draws on ART when he writes of the cognitive benefit of walking in nature. The "soft fascinations" of nature can positively influence cognition (Smith, 2010, n. p.).

Nature can assist in restoring our psyche; at the same time, environmental destruction is capable of equally strong impacts. Kidner's (2007) research highlights an increase of depression in times of ecological peril, suggesting that humankind's emotional experience is intertwined with the state of the natural world. This thought is exemplified with Albrecht et al.'s (2007) research on solastalgia: the idea that when our immediate environment is threatened we can feel pain and homesickness. The emotional connection humans have with their environment can at times appear so deep-seeded that we do not even realize we have it until it is disrupted. Examples of this lack of awareness would be from those who deny the existence or significance of environmental problems, and the perceived apathetic responses to environmental issues, which Lertzman (2008) claims is actually an indicator of human denial of ecological crises because the truth is too painful to consider. This literature posits, then, that if we protect ourselves from the painful truth of environmental problems, it must be that we are, in some way, emotionally tied to our natural world and are trying to protect ourselves from feeling pain.

Understanding the emotional connection we experience when we are outdoors must go beyond textual analysis. McIntyre (1999) contended, "if we are to understand these experiences fully, we need also to focus on participants' immediate conscious experience (e.g., thoughts, images, feelings and sensations) during adventure recreation" (n.p.). With this in mind, this thesis research was designed to identify signs of the biophilia tendency while participants experienced the Hooksum Outdoor School program. The fieldwork had to be experiential and immersive in order to fully understand participant experience. 


\section{The Biophilia Tendency}

Just as destructive environmental action can impact our psyche and emotions, so too can we feel love, connection and well-being with the environment. The term biophilia is often used to explain "the innately emotional affiliation of human beings to other living organisms" (Wilson, 1993, p. 31). Being commonly understood as the "love for living nature" (Soulé, 1993, p. 441), many researchers are exploring this love humans hold for their environments. There are other terms used in research that relate to the biophilia tendency. Albrecht (2010) proposes the idea of soliphilia; that is, a feeling of attachment to one's natural region, often their home environment. This contrasts biophilia's wider scope of affiliation with natural systems. Furthermore, researchers like Sobel (1998) hope to counteract the growing human disconnect from the natural world with ecophilia, a term he uses in explaining "children's biological tendency to bond with the natural world" (n. p.). This is largely similar to the biophilia tendency.

The study focused specifically on the biophilia tendency, using the definition Wilson (1993) popularized when he argued that biophilia is an innate tendency within humankind to emotionally connect with other living organisms. His research identifies the psycho-social dimensions of biophilia, and demonstrates that humans pass down learning rules through generations that reflect affiliations for nature, including living near water, fear and aversion to particular species, and feelings of awe and wonder (Wilson, 1993). His research also posited an evolutionary and biological basis for the biophilia tendency, an argument that is supported by Kellert's (1993) work. Kellert insists that there are universal expressions of biophilia, which are rooted within nine biological evolutionary dependences- also called valuations of nature (Kellert, 1993, p. 44). 
Table 1

Kellert's (1993) Nine Dimensions of the Biophilia Tendency

\begin{tabular}{cc}
\hline & Biophilia Tendency \\
\hline Dimension & Focus \\
\hline Utilitarian & Physical benefits derived from nature \\
Naturalistic & Satisfaction from direct experience \\
Ecological-Scientific & Precise and systematic study/inquiry \\
Aesthetic & Feelings of awe at natural beauty \\
Symbolic & Nature used as metaphor, communication, \\
& and expression \\
Humanistic & Deep emotional attachment or love \\
Moralistic & Spiritual reverence for nature \\
Dominionistic & Need to master the environment \\
Negativistic & Fear and alienation from nature
\end{tabular}

Note. This table was created as part of the research process for this study and adapted from Kellert's (1993)

The Biological Basis for Human Values in Nature. See reference list for full article reference.

While they are unique, each dimension requires a dependent relationship on nature and has provided a biological evolutionary advantage to humans (Kellert, 1993). For example, a naturalistic dimension has possible evolutionary roots in the desire to explore the living world; this aspect of the biophilia tendency is beneficial, as individuals gain increased knowledge, physical fitness and well-being, which provide advantages for human evolution (Kellert, 1993). Kellert's research suggests that the biophilia tendency operate in a similar way to other evolutionary traits, and a biophilia tendency could stem from a long line evolutionary biology that allowed for the other eight dimensions' associated advantages. Orr (2011a) pondered the possibly that biophilia is innate, and stated, "It would be surprising indeed if several million years of evolution had resulted in no such affinity" (p. 33).

The biophilia tendency, from both an ecological and psychological perspective, is central to this research. I wished to examine loving feelings, in a coastal context, in order to shed light on the relationships that may exist between humans and the ocean, and contribute to the literature by examining how the biophilia tendency is nurtured and/or develop through outdoor adventure 
training.

\section{Phenomenological Psychology}

Phenomenology, as both a research method and philosophy, aims to "emphasi[ze] the attempt to get to the truth of matters, to describe phenomena (...) that is as it manifests itself to consciousness, to the experiencer" (Moran, 2000, p. 4). In this sense, phenomenology describes the view of the individual. Amedeo Giorgi popularized phenomenological psychology as a methodology; his research sought to analyze an individual's description of an experience while discovering the underlying psychological meaning of the experience (Giorgi, 2006).

Researchers have established common theories in phenomenological psychology, and though my research follows Giorgi’s methodology, it also recognizes Patterson's (1965) summary of phenomenological psychology theory. This theory rests largely on Combs and Snygg's (1959, as cited in Patterson, 1965) eight assertions: (a) individuals are active organisms trying to organize their world; (b) the perceptual or phenomenal field is the name given to how an individual organizes the world (other researchers use the term lifeworld); (c) individuals only act on the basis of their perceptions; (d) phenomenal fields are hypothetical constructs; (e) when studying behavior, phenomenology looks at internal frames of references, not external; (f) phenomenal fields determine individual behavior, and if one understands the phenomenal field and projects it in to the future, one can predict behavior; $(\mathrm{g})$ the self is part of individual phenomenal fields; (h) an individual's perception changes under conditions that determine it necessary to do so in order to preserve the self.

Many researchers have used phenomenology and/or psychology to better understand experiences in nature. Ketterer (2010) studied emotional and psychological change amongst thruhikers of the Appalachian Trail. Using Interpretative Phenomenological Analysis (IPA) he searched for psychological change within hikers along the trail, and analyzed how hikers were 
making meaning of their experiences (Ketterer, 2010). In structuring his results into themes, he noted that almost all hikers experienced a psychological change while hiking. His interview questions, specifically those focused on inner change and the most meaningful parts of the experience, were helpful in structuring this study.

Other researchers have used phenomenology to study occurrences of personal transformation within participants of outdoor education programs. Rowley (2010) studied personal reflections of Grade 10 participants in the TREK outdoor education program, with a focus on what the experience meant to them. She found an emergence of common themes, including self-reflection and changes in pro-environmental behaviour. Her argument that outdoor challenges and experiences can contribute to transformation supports the view that what individuals experience in the natural environment is interlinked with the inner self. With this in mind, it is my view that a project aimed at loving relationships with nature during outdoor adventure training must utilize a phenomenological and/or psychological approach.

\section{The Pacific Coast}

The above literature has noted the link between cultivating personal growth (skills or values-based) and being outdoors, the impact nature has on the human psyche, the proposition of the biophilia tendency, and examples of phenomenological psychology in theory and practice. The importance of understanding outdoor experiences and fostering relationships with nature stems from the view that caring about the planet motivates humans to protect and conserve it (Orr, 2004; Perkins, 2010; Sobel, 1998).

It is also important to recognize the literature surrounding the selected region for this study. Pacific Northwest ecosystems, specifically the west coast of Vancouver Island, consist of "rugged coastlines punctuated by stunning surf-swept beaches (....) backed by a temperate rainforest of giant cedar, hemlock, and Sitka spruce" (Alderson, 2004, pp. 9-10). He notes that 
Vancouver Island provides some of the most renowned surfing and sea-kayaking environments. 
"Literally it is everything about the ocean that attracts me. And satisfies me to a level, a level that's very profound to me. And it resonates, ah, it resonates with me like nothing else." 


\section{Chapter 3: Methods}

This chapter presents an outline of the methodology used in the study. Data collection methods and analysis are shown. The determination of reliability, reflexivity, and validity will also be discussed, followed by delimitations and limitations of this study and ethical considerations.

This study is a concurrent nested design, in which a quantitative method is embedded in a predominately qualitative study (Tashakkori \& Teddlie, 2003). The benefit of using a concurrent nested approach is to view the data in an alternate way and provide validity to the study. It also allows the researcher to look at general themes across participants as well as specific participant stories. The design was primarily based within a phenomenological framework.

\section{Hooksum Outdoor School}

Hooksum Outdoor School is located in Hesquiaht Harbour, on the west coast of Vancouver Island. Every May the owners of the School host a 28-day West Coast Outdoor Leadership Training program. This program allows participants to live in tents on the beach, while engaging in "adventure-based, experiential learning" and "[1]earning about the natural world of Hesquiat Harbour, and indigenous values and culture" (Hooksum Outdoor School, 2011). The May program creates a space where:

[p]articipants have the opportunity to hone their skills in wilderness camping, surfing, canoeing, sea kayaking, hiking and backpacking while gaining an intimate knowledge of the Pacific coastal environment. Participants will leave the program with increased comfort and confidence levels in their outdoor abilities. (Hooksum Outdoor School, 2011, n.p.) 
Each year the program involves 7-12 participants who remain relatively isolated from the nearest community, Hot Springs Cove. For the May 2012 program, six participants including myself attended.

Participants were recruited via a letter electronically sent out by Hooksum in preparation for the May 2012 program. This e-mail outlined the research to all those attending Hooksum and was reiterated upon arrival at Hooksum. Before program activities began, I introduced myself to the participants, stated the research aims, and made my intentions clear. The five participants as well as staff members who consented to my study were adults between the ages of 22 and 45 who lived in coastal British Columbia (though not all individuals were from the coast). Participants included artists, musicians, photographers, and outdoor enthusiasts. Individual narratives (in Chapter 4) provide insight to each participant.

\section{Phenomenology}

The study relied upon phenomenological research methods. Phenomenology is "interested in the common features of the lived experience" (Starks \& Brown Trinidad, 2007, p. 1375). As an empirical research method, phenomenological inquiry seeks to collect examples of lived experiences and bring meaning to the surface of these experiences (Phenomenology Online, 2011). Since researchers such as Perkins (2010) describe biophilia as "a psychological phenomenon of being instinctively attracted to all life" (p. 455), it made sense then, to approach the research questions from both a phenomenological and psychological angle. Phenomenological psychology aims to understand the psychological meanings of how an individual expresses their experience (Giorgi, 2006).

The study was originally designed to employ brief pre- and post-program interviews, in addition to in-depth, on-site interviews and participant observation. In April 2012 this approach was revised, as it was difficult to elicit participant involvement prior to the program start date. It 
was imperative that the research methods chosen help analyze how emotional feelings of love towards nature, or a biophilia tendency, might shift during the 28-day outdoor adventure training at Hooksum. The research method used to capture this complexity was a pre-post post-program questionnaire, completed one day before the end of the program, asking participants to reflect upon and compare how they felt before starting the program and at the time of the questionnaire (see Appendix D for complete questionnaire).

As feelings of love are both emotional and cognitive, the use of the pre-post postprogram questionnaire and second interviews balanced in-depth interviews, allowing for deeper analysis of participants' experiences from the perspectives of emotional reflection and psychological interpretation. The nature of this study (searching for the biophilia tendency, or feelings of love for nature) is highly qualitative. I wished to explore an emotional experience within participants at Hooksum; qualitative research enabled data collection to go deeper into their subjective experience to understand each meaningful event from a phenomenological approach.

The research included multiple modes of data collection in different phases of the 28-day program. Participant observation was recorded in field notes throughout the entire program. Indepth interviews were conducted either in tents, on the beach, or beside the creek at Hooksum, in the last week of the program. Questionnaires and second interviews were conducted one day before departure.

\section{Data Collection}

Data was collected during 28-days of fieldwork on site at Hooksum Outdoor School on Vancouver Island. Fieldwork involves collecting data in a naturally occurring setting in order to understand what's happening, usually with in-depth interviews and participant observation (Payne \& Payne, 2004). For this study, fieldwork included participant observation, semi- 
structured in depth interviews, a pre-post post-program questionnaire, and brief second interviews before departure.

\section{Participant Observation.}

Observing participants during Hooksum Outdoor School assisted in understanding how participants were making meaning of their experiences, a goal of phenomenology (Starks \& Brown Trinidad, 2007). I conducted participant observation following the four-step process described by Payne and Payne (2004), by (a) flagging events mentally and assigning them an image or place as they happened; (b) jotting things in a field notebook, expanding as much as possible to help recall events later; (c) compiling an end-of-day field entry with the detailed events of the day, including my reflections and feelings on everything that I saw and felt, being sure to include admissions of things missed; (d) my notes were organized and catalogued systematically and included all occurrences, not just things thought to answer the research questions (Payne \& Payne, 2004).

From observations, I interpreted if and how participants were cultivating a love for coastal environments over the course of the program, or the emotional processes they were experiencing while in the coastal environment at Hooksum. Every day of the program was recorded in a field journal, resulting in 28 days of field-notes.

\section{In-depth Interviews.}

Semi-structured interviews allowed me to further explore the lived experience of select participants. Phenomenology Online (2011) notes:

In phenomenological human science the interview first of all serves the very specific purpose of exploring and gathering experiential narrative material, stories or anecdotes, that may serve as a resource for developing a richer and deeper understanding of a human phenomenon. (n. p.) 
Throughout this exploration, I witnessed participants' emotional journeys throughout the Hooksum program. I also witnessed how each participant acted in response to the personal changes and reflections during the 28 days. Five participants (83\%) consented to an in-depth interview (see Appendix $\mathrm{C}$ for questions). Four of those participants also consented to a pre-post post-program questionnaire and second interview. This data analysis examines the four participants who agreed to participate in an in-depth interview as well as a pre-post post-program questionnaire and second interview. It examines the experience from their point of view, and attempts to understand how they made meaning of their Hooksum Outdoor School experience. I recorded and transcribed each in-depth interview, making notes during the interview. Brief second interviews were recorded and notes were made during the interview.

\section{Pre-post Post-program Questionnaires.}

The customized pre-post post-program questionnaire helped answer the main question, "what is the relationship between outdoor adventure training and the biophilia tendency in participants learning and living in Pacific coastal environments"? Additional demographic data collected included names of cities/towns/places of participant's residences and proximity to the coast in those residences.

The questionnaire involved open-ended questions relating to demographic information and reasons for taking this program. Some of the information was a direct replication of the introductory questions during the in-depth interview, and was meant to allow participants to feel comfortable reflecting on how they engage with familiar coastal environments.

Demographic data, including proximity to the coast of participants' home residence, was gathered during the in-depth interview and the questionnaire, in part as a way to introduce participants to comfortable and familiar questions. Demographics were also meant to see if there was a relationship existing between those who normally live near the coast and expressed a 
biophilia tendency; at the same time, it could be beneficial to know if participants who do not live near coastal environments find the environment to be foreign or exotic and influence changes in biophilia levels. I also thought it would be interesting to see how easily participants were able to recall the closest bodies of water to them, and the ways in which they engage with natural bodies of water on a daily basis.

The questionnaire also included the Love and Care for Nature (LCN) scale (Perkins, 2010). Love and care for nature has been defined as "a deep love and caring for nature which includes a clear recognition of nature's intrinsic value as well as a personal sense of responsibility to protect it from harm" (Perkins, 2010, p. 456). LCN was developed in response to the limitations of the Connectedness to Nature Scale (CNS), "a measure designed to tap an individual's affective and emotional connection to nature" (Mayer \& Frantz, 2004, p. 505). As there has been some debate as to whether CNS effectively measures the emotional dimension of connectedness to nature or if it is based more on cognitive sense of connection (Perkins, 2010), LCN seeks to deeper explore the emotional aspect of the human-nature relationship (Perkins, 2010). Participants were presented each of the 15 statements of the LCN and were asked to reflect on how they would respond to this question before the program (indicated by a Likert scale of 1-7 on the left side) and at the moment of the questionnaire (indicated by a Likert scale of 1-7 on the right side). Participants filled these out on site with myself present to answer questions or clarify how to fill out the scale. There was no direction on how to answer the questions and participants were encouraged to answer honestly and as in-depth as they chose.

\section{Second Interviews.}

The second interview consisted of brief questions of what participants would take home from this experience, to demonstrate any changes that they may have liked to vocalize since the in-depth interview or that may not have been present to me in my observations. Particular 
questions such as "Please describe your relationship with the ocean" are duplicated from the indepth interviews to look for a change process throughout the program. These interviews were recorded and notes taken throughout each of them.

\section{Data Analysis}

\section{Participant Observation.}

I recorded observations of interaction patterns, actions, verbal and non-verbal communication, in order to balance interviews data (Eriksson \& Kovalainen, 2008). Participant observation was analyzed by looking for repeated patterns, themes, and behaviour from observation notes, which were aimed at discovering how participants were acting on their love, if any, for coastal environments. As Kolb (2008) has written, observation notes are examined as when looking for unique or repeated behaviour; behaviours become the basis for interpretations and recommendations.

\section{In-depth Interviews.}

Semi-structured interviews on site were interpreted using Interpretative Phenomenological Analysis (IPA) (Smith \& Eatough, 2007). Following the IPA format of Smith and Eatough (2007), in-depth interviews were transcribed, during which I wrote down initial thoughts and comments that were deemed significant. Then transcripts were re-read with notations placed in the margins of content that stood out as interesting and common themes; afterwards, I clustered the themes of each interview into higher-order themes and wrote a narrative (Smith \& Eatough, 2007). This analytical method allowed me to see themes that emerged relating to, if and how participants cultivated a love for coastal environments, and how they acted on this love.

Eatough and Smith (2006) outlined the stages of IPA clearly and this was the guide for four participant stories. It required (a) reading the transcripts repeatedly and using the left-hand 
margin to write down anything that seemed significant; (b) re-reading the transcript and using the right-hand margin to transform first-stage notes into specific themes or phrases; (c) establishing connections between themes and patterns and clustering them with a descriptive label, termed higher-order theme; (d) producing a table with each higher-order and clustered themes; (5) writing a narrative that interplayed (moved between) extracts from each participant's account with a description of the interview.

\section{Pre-post Post-program Questionnaires and Second Interviews.}

The questionnaires and second interviews were analyzed by looking for repeated themes and patterns. The LCN scales were tallied in an excel spreadsheet that calculated each participant's response values, looking specifically at item response distributions (Perkins, 2010); that is, the comparisons between values of before the program and the end of the program.

\section{Reliability and Reflexivity}

In order to provide credibility for the research, various measures were taken to ensure reliability. Reliability in qualitative research resolves around a researcher's trustworthiness (Golafshani, 2003) and ability to provide rigour in research methods. It remained my goal to maintain a high professional standard of research and encouraged reflexivity, that is, selfawareness and self-critique (Payne \& Payne, 2004) throughout all steps of the research process. This included utilizing a variety of data collection methods (a) participant observation fieldnotes; (b) interviews and accompanying interpretations and notes; (c) questionnaires (with shortanswer and Likert scale components). Member checking with participants gathered feedback on my interview interpretations, and IPA as an analysis tool provided thick, rich descriptions of participant stories, two steps that enhance research credibility (Creswell \& Miller, 2000). In addition, this thesis is subject to academic review, a process of challenging assumptions and pushing the research forward by "a person who is familiar with the research or the phenomenon 
being explored" (Creswell \& Miller, 2000, p. 129). All these measures ensured the data collection and interpretations were as accurate as possible and that the research is trustworthy. I was diligent in creating a research collection plan before fieldwork began to maintain accountability to the standards of the methodology.

Throughout this research, I was an active participant in Hooksum Outdoor School's 28day program. As such, I was experiencing the same group and environmental dynamics as the research participants, and have my own personal story of the experience. When analyzing data, then, I was looking through a lens of someone that truly believes biophilia can be nurtured by outdoor adventure training, which left me with biases in my interpretations. However, I felt strongly that by developing relationships with my participants, living and experiencing the program simultaneously with them, and holding myself accountable to a strict and rigorous research plan, I would not only be capable of conducting reliable research of Hooksum Outdoor School's participants, but as someone who values each participant's story, I would strive to present them as accurately, and interpret as honestly, as possible.

\section{Limitations}

I did not interview or observe past participants of the program. While those encounters would undoubtedly provide intriguing information, the scope of this project was to examine the lived experience as it occurs within the participants of the 28-day Hooksum program in 2012. Two staff members were observed and expressed interested in being interviewed (using pre-post post-program questionnaires and the same questions as participants' second interviews). Their reflections are included in the observation results and discussion. The research sample size was too small to hold statistical power, and this was recognized at the time of study design. While originally the study hoped to gather information in a pre-program survey, this tool was revised based on limited response. The redesigned questionnaire allowed participants to reflect on their 
own change process, providing an authentic representation of each individual's emotional changes during the program. A quantitative method (LCN scale) was used as another way to view data.

Five participants $(83 \%)$ consented to a semi-structured, in-depth interview. This study included four stories from participants who also consented to the questionnaire, and while this sample size may seem small, the extensive and immersive data collection during the program generated rich, deep narratives for each individual. The sample size was also limited to participants who were independently interested in learning in this coastal environment, had a desire to engage in outdoor adventure training, and chose to do the program; however, it is my belief that the deep exploration of the cognitive and emotional processes occurring within participants outweighs this limitation.

\section{Ethical Considerations}

The research involved the participation of human research subjects and required a detailed ethical review form, which was submitted to the Ethical Review Board at Royal Roads University before fieldwork began. All staff at Hooksum Outdoor School and every participant in the program, while consenting to the research or not, was made aware that graduate-level fieldwork was being conducted alongside the program. There was no obligation to take part in the research while completing the 28-day program and participants were allowed to withdraw at any time. Participants who did not consent to any aspect of the study $(\mathrm{N}=1)$ are mentioned nowhere in participant observation fieldnotes and were not interviewed.

As the research was conducted at Hooksum Outdoor School, a school run by members of the Hesquiaht First Nation, the study involved participants of various cultural backgrounds and elements of Hesquiaht cultural knowledge were included in the program's teachings. However, the nature of this study was not to examine First Nations' environmental programming or their 
relationships with coastal environments; therefore, the ethical considerations of involvement with aboriginal individuals or communities was not outlined in the project's Request for Ethical Review. The project's aim is to discover participants' (regardless of cultural, race, or ethnic backgrounds) stories of their experience at Hooksum, and if they exhibit a biophilia tendency throughout the program.

All data obtained for this research remains confidential. It is stored on a laptop that is password protected and in a filing box with the researcher. As outlined in this study's Request for Ethical Review, data was gathered to be used by the researcher, used to interpret participants' experience at Hooksum Outdoor School, stored in private files, not analyzed by any software that would collect information, and retains participant anonymity. Revealing participant information is omitted from interview extracts, and names of participants and staff changed. 
I'm so good at kayaking!

I'm so good at kayaking!

I'm so good at kayaking, I'm basically a kayak ninja!

A song for Alex, Jeremy, and Jonas 


\section{Chapter 4: Findings}

A summary of the findings from the study is outlined in this chapter. First, four themes developed from 28-days of participant observation are presented. Second, results of four participants' pre-post post-program questionnaire, second interview, and Love and Care for Nature (LCN) scale are summarized and tabled. Lastly, Interpretative Phenomenological Analyses of the in-depth interviews are presented in four narratives.

\section{Participant Observation}

Analysis of field-notes and participant experiences were summarized into four emergent themes and an additional fifth less prominent sub-theme. Themes include (a) expressing feelings of awe and serenity in nature's beauty; (b) object collection; (c) familial atmosphere and closeness between group members; (d) energy boosts when in or on the water; (e) overcoming fears and self-doubt.

\section{Theme 1: Expressing feelings of awe and serenity in nature's beauty.}

Throughout the program, all participants had moments where they noticed the surrounding environment and/or wildlife and expressed a feeling of awe or wonder. Examples of this included (a) group of participants growing silent when an osprey flew overhead; (b) comments of "wow" when finding a grouse nest; (c) becoming silent and still when seeing a sow and cubs, then excitedly recanting the event to others; (d) saying "it's beautiful" in reference to the mountains and ocean; (e) noting that the waves seemed mesmerizing to watch or were soothing each night as they drift off to sleep. Participants vocalized on multiple occasions that the setting provided the "best classroom" or "best living room". Two excerpts from Day 15 in the field journal illustrate a feeling of wonder at the natural environment: 
After dinner, Morgan, Casey, Elijah and I laid on the grass between tents and stared at the eagle and osprey flying above us. Morgan stretched out his arms and looked up at the sky and said, "This is the best place." Casey agreed.

Listening to the sound of the Pacific, I thought I could lie there for a really long time and it would be perfect.

These feelings were vocalized early in the program and continued to the end. Here are additional excerpts:

We swam in and out of caves, taking funny water pictures... and as we swam out of a cave we saw a mama black bear and two cubs on the beach. They ran off once they saw us, but we were all a bit speechless when we saw them. It was one of the first things we excitedly told the others about once we returned. (Day 12)

We saw four eagles flying low to catch fish... like the osprey, we were mesmerized. (Day 12)

After lunch we continued with the radio course, and went into [the house] to listen to the radio manual on CD. I sat on the couch with Jeremy and Alex and Alex mentioned, "Look at the beautiful TV," gesturing to the ocean outside. (Day 22)

\section{Theme 2: Object collection.}

Many participants collected objects from the area surrounding Hooksum Outdoor School to take back home with them. These were objects that they found to be interesting or pretty, and included shells, rocks, and bones. Participants shared this information with others, and presented objects they planned to take back. The purposes of these collections were either for gifts, to display in their homes, or to make into jewellery. Excerpts demonstrate these behaviours:

At the night-time beach campfire Elijah mentioned [finding] a dried starfish for a friend. Elijah also did a good beach comb for seashells to make a "hippie necklace". (Day 7) 
Alex said, "both beaches (Hooksum and Hesquiaht Point) have such beautiful things". Both Alex and Elijah collected urchin carcasses- they look like beautiful shells. (Day 8)

On the walk back from the beach I noticed both Alex and Casey were collecting rocks and shells. (Day 11)

\section{Theme 3: Familial atmosphere and closeness between group members.}

Throughout the program, group members became increasingly comfortable sharing

personal information with each other and began to act in a way similar to a family unit. After the first week, participants were struck by the amount of time that had passed, and mentioned that it felt like much longer. The comfort level with each other was illustrated by the willingness for participants to offer up personal information regarding past experiences, feelings, dreams, personal loss, depression, traumatic experiences, and turning points in their lives. In addition, when group members left (either participants leaving the program early or instructors finishing their courses), someone often noted their absence, mentioning they felt like people were missing. At dinner Jeremy mentioned he kept feeling like we're missing people. I completely agree...it's still beautiful and a lot of learning to do, it's just different. (Day 20)

It's nice to be announced one-by-one at lunch to congratulate us individually and present our cards. It's great to have everyone in the group cheer you on. (Day 21)

Some people went to bed early so Alex, Jeremy, and Morgan decided to go down to the beach and then started making a lean-to fort with wood and branches. Elijah and I joined in and we had a great beach fort. We had a fire down on the beach and went around the fire saying our highlights of the program. People mentioned great memories, beautiful scenery, good people and laughs. Then we had a sing-along and curled up in our forts (discovering that they were a bit leaky). I woke up warm and dry, thankfully. I don't think I can say the same for everyone. It was really nice to have us all squished together on the beach. (Day 23/24) 


\section{Theme 4: Energy boosts when in or on the water.}

It was incredibly noticeable that all participants expressed drastic energy boosts when learning outside on the beach and in/on the water, compared to learning inside the longhouse. What's more, these boosts were not unique to sunny weather: conditions that were rainy but didn't prohibited paddling or swimming were also linked to positive bursts of energy.

Participants laughed and smiled more, and had high energy when learning outdoors and in sunny weather with waves that allowed for kayaking or surfing. When the weather was rainy or overcast the group's energy did not drop if they were able to paddle, swim, or surf.

The energy when learning inside the longhouse was stressed, exhausted, and tense at times, in part due to the overwhelming information, length of time spent with the group, and inability to be in or on the water. Furthermore, when the weather included weak precipitation but strong winds that prohibited a day on the water, the energy was noticeably lower than much rainier days with safe waves. An excerpt from Day 21 highlights some of the rainiest weather of the trip and the group's energy when able to surf:

The waves are coming in perfect sets. I find it so mesmerizing to watch the waves. Elijah talked about how great the surf was, and Morgan stood looking at the ocean and said, "I feel like I'm in this beautiful place."

In addition, the group's energy is illustrated in these excerpts:

Everyone seems a lot more excited to go and learn outside on the beach in the First Aid course. Our energy is noticeably higher and more alert. (Day 3)

The wind picked up fast: whitecaps started and we had to head in after only an hour and fifteen on the water. However, there were mini waves so Jonas showed us how to surf them into shore. I loved this! So much fun riding them in, even if they were mini. I felt it pull me in and lift me up, and I could hear Alex yelling "Woo!" beside me. (Day 16) 
We each taught the strokes we were assigned to teach and the energy was through the roof high. Alex had the giggles and a laughing fit that resulted in crying, Jeremy... started laughing, Jonas couldn't stop mentioning our crazy energy well into the evening campfire, and I was laughing and yelling and singing uncontrollably. I think it has to do with being able to be on the water for a long time finally, after two days of only an hour or so. (Day 18)

In addition to this high energy on the water, some participants explained that they were experiencing a feeling of euphoria, or a comparison to being drunk or stoned when coming out from the water. A campfire conversation from Day 16 reads:

Morgan, Elijah, and Jonas were saying that when they get out of the ocean sometimes there's a feeling like you're still moving. Morgan compared it to being stoned- he said (of the feeling of still moving like in the ocean) "I love it".

The following two excerpts continue this theme:

I interviewed Morgan down by the water. He spoke a lot about a "euphoric" experience, or endorphin-releasing sensation, while in the water. (Day 24)

Elijah added...every time he gets out of the water he feels high or drunk. (Day 27)

\section{Theme 5: Overcoming fears or self-doubt.}

Though not as prominent as the other themes throughout the 28 days, some group members overcame some sort of fear or self-doubt while at Hooksum. One participant mentioned overcoming a fear of dark water during the kayaking and lifesaving course. One participant mentioned that the program reaffirmed what he was meant to be doing in his life. As a participant in the program, I overcame self-doubt during the 24-hour solo on Day 26. Here is an excerpt: 
We were only give three matches and this morning after breakfast we practiced with 3 matches. It took me 5 or 6 so I was pretty nervous. I made my fire and my first match got snuffed out. So I took a deep breath, readjusted everything... and it caught in the second match... I think one of the greatest feelings for me during this month was getting that fire started. I was so happy and proud of myself.

Analysis and interpretation of these themes will be discussed in Chapter 5.

\section{Pre-post Post-program Questionnaires and Second Interviews}

Four of the five participants participated in end-of-program questionnaires and second interviews. These were filled out and conducted approximately one day before program departure. Questionnaires were read and analyzed for emergent themes. Results of their questionnaires can be seen in Table 2.

Table 2

Emergent Themes from Four Participant Pre-post Post-program Questionnaires

\begin{tabular}{|c|c|c|c|c|c|c|c|c|c|}
\hline $\begin{array}{l}\text { Emerging } \\
\text { Theme }\end{array}$ & $\begin{array}{l}\text { Living in } \\
\text { coastal } \\
\text { B.C. }\end{array}$ & $\begin{array}{l}\text { Participants' } \\
\text { estimate of } \\
\text { closest body } \\
\text { of water to } \\
\text { home: }>2 \mathrm{~km}\end{array}$ & $\begin{array}{l}\text { Spend } \\
\text { time } \\
\text { with } \\
\text { water }\end{array}$ & $\begin{array}{l}\text { Spend } \\
\text { time } \\
\text { with } \\
\text { water: sit } \\
\text { or } \\
\text { meditate }\end{array}$ & $\begin{array}{l}\text { Spend } \\
\text { time } \\
\text { with } \\
\text { water: } \\
\text { walking }\end{array}$ & $\begin{array}{l}\text { Taking } \\
\text { program for } \\
\text { certificates/ } \\
\text { career help }\end{array}$ & $\begin{array}{l}\text { Taking } \\
\text { program to } \\
\text { experience } \\
\text { culture }\end{array}$ & $\begin{array}{l}\text { Taking } \\
\text { program } \\
\text { to get } \\
\text { away } \\
\text { from } \\
\text { home }\end{array}$ & $\begin{array}{l}\text { Taking } \\
\text { program } \\
\text { to find } \\
\text { myself }\end{array}$ \\
\hline Participants & 4 & 3 & 4 & 2 & 4 & 3 & 1 & 1 & $\overline{1}$ \\
\hline
\end{tabular}

Note. Table displays the numerical value of participant answers that included nine general themes.

Participant answers were analyzed and grouped according to common phrases or terms used. All participants were living in coastal British Columbia at the time of the program, and all participants spend time near natural bodies of water in their home communities. A copy of the questions can be found in Appendix D.

Second interviews were also read for emergent themes. A copy of the questions can be found in Appendix E. Results of the second interviews can be seen in Table 3. 
Table 3

Emergent Themes from Four Participant Second Interviews

\begin{tabular}{|c|c|c|c|c|}
\hline Question & Alex & Elijah & Morgan & Quinn \\
\hline $\begin{array}{l}\text { What is the first } \\
\text { impression that comes } \\
\text { to mind when you } \\
\text { hear the word } \\
\text { "ocean"? }\end{array}$ & $\begin{array}{l}\text { Great big body of water } \\
\text { Home }\end{array}$ & $\begin{array}{l}\text { Calmness } \\
\text { Danger } \\
\text { Lot to learn }\end{array}$ & $\begin{array}{l}\text { Crabs } \\
\text { (collecting } \\
\text { crabs/shells/childhood } \\
\text { memories) }\end{array}$ & $\begin{array}{l}\text { Home } \\
\text { (grew up/family) }\end{array}$ \\
\hline $\begin{array}{l}\text { Please describe your } \\
\text { relationship with the } \\
\text { ocean }\end{array}$ & $\begin{array}{l}\text { Spent a lot of time near } \\
\text { it/want job related } \\
\text { Energizing }\end{array}$ & $\begin{array}{l}\text { Not as strong as } \\
\text { childhood } \\
\text { Don't really have one } \\
\text { know, getting stronger } \\
\text { (especially surfing) }\end{array}$ & $\begin{array}{l}\text { Place I know I'll always } \\
\text { live close to } \\
\text { Held as special/positive } \\
\text { thought }\end{array}$ & $\begin{array}{l}\text { Big part of me } \\
\text { Way of life } \\
\text { (nutrition/seafood) }\end{array}$ \\
\hline $\begin{array}{l}\text { Does being in coastal } \\
\text { environments } \\
\text { produce meaning for } \\
\text { you (about yourself, } \\
\text { your past, present, } \\
\text { future, relationships, } \\
\text { etc)? }\end{array}$ & $\begin{array}{l}\text { Everyone I love is } \\
\text { there } \\
\text { Place to read/think/sing }\end{array}$ & $\begin{array}{l}\text { It means this is where } \\
\text { I come from }\end{array}$ & $\begin{array}{l}\text { Brings more calm than } \\
\text { meaning }\end{array}$ & $\begin{array}{l}\text { Familial (fishing with } \\
\text { dad, present familial } \\
\text { relationships, outdoor- } \\
\text { related meaning to } \\
\text { family members to carry } \\
\text { into future) }\end{array}$ \\
\hline $\begin{array}{l}\text { Has your relationship } \\
\text { with the ocean } \\
\text { changed throughout } \\
\text { Hooksum's program? }\end{array}$ & $\begin{array}{l}\text { No- maybe a little more } \\
\text { respect, but that was } \\
\text { always there. Learn } \\
\text { more about this } \\
\text { particular area }\end{array}$ & $\begin{array}{l}\text { Yeah- going to surf } \\
\text { more and be more } \\
\text { active }\end{array}$ & $\begin{array}{l}\text { No- had past } \\
\text { understanding of the } \\
\text { ocean and it's effects on } \\
\text { me. It's perfect }\end{array}$ & $\begin{array}{l}\text { Yes- understanding } \\
\text { resources, biodiversity, } \\
\text { more aware of what's } \\
\text { going on in relation to } \\
\text { preserving life on coast }\end{array}$ \\
\hline
\end{tabular}

Note. Data collected from four participants in a second interview after the pre-post post-questionnaire.

Answers in bold show emerging themes or points of interest.

The sample is too small to draw claims from, but an interesting theme that emerged is the

feeling of home. For example, all participants lived in coastal B.C. (and quite close to the water), and two participants mentioned home when asked what they thought of when they heard the word ocean. All four participants spend time near the water, and three participants mentioned family/loved ones or "where I come from" when asked to describe their relationships to the ocean, supporting the theme of home.

Another point of interest is that two participants said that their relationship with the ocean changed during the program, and those who said it did not change mentioned either an existing positive relationship or gaining a bit more knowledge/respect while at Hooksum.

\section{LCN Scale Results}

Questions in the LCN scale were answered in a Likert scale with the numeric value 1 
representing strongly disagree and 7 representing strongly agree. Participants' item response distributions both before the program and at the time of the questionnaire (one day before departing the program) are presented below. Questions 1-15 demonstrate the item response values before the program for each statement, and questions 16-30 demonstrate the item response values before departure, using the same statements and order. To read the full LCN survey in the pre-post post-program questionnaire, see Appendix D. A large excel spreadsheet calculated all participants' results (Appendix F). Total item response values are displayed in Table 4.

Table 4

Item Response Distributions for Four Participant Love and Care for Nature (LCN) scales

\begin{tabular}{cccc}
\hline Participant & Total Pre & Total End & Difference \\
\hline Alex & 100 & 105 & 5 \\
Elijah & 95 & 95 & 0 \\
Morgan & 84 & 84 & 0 \\
Quinn & 77 & 105 & 28
\end{tabular}

Note. Data collected on site from four questionnaires. This table displays only total response distributions.

Although too small a sample size to be statistically significant, two participants noted a change in item response values between before the program and now (one day before departure). The statements in which both participants had an increase in values after experiencing the program are: When in natural settings I feel emotionally close to nature (a difference of +1 for each); I enjoy learning about nature (a difference of +2 and +1 ); and Ifeel a personal sense of interconnectedness with the rest of nature (a difference of +1 and +3 ).

All participants gave the statement, I often feel a sense of wonder when I am in unspoilt nature, a high item response value, with three participants giving a value of 7 both before the program and at the end of the study. One participant gave the statement a value of 5 before the program and 7 at the end of the program.

The statement I need to have as much of the natural environment around me as possible 
showed virtually no increase or an exceptionally high value. This is in contrast to the participant observation theme of object collection.

All participants gave 7 values to the LCN statement I feel content and somehow at home when I am in nature.

\section{Individual Participants}

This section explores the stories of four participants during Hooksum Outdoor School. Each of the four participated in an semi-structured in-depth interview, approximately one week before leaving the program. Analysis followed Smith and Eatough's (2006) guidelines for Interpretative Phenomenological Analysis. This section presents a narrative illustrating how each participant vocalized personal change (intellectual, emotional, and/or biophilic) during the program, and my interpretations of the data.

The narratives do not necessarily follow an interview's chronological order, but do highlight the most significant points that emerged from each participant. Each higher-order theme (descriptive label for related themes from each interview) is represented by a quote, followed by the corresponding transcript extracts. The letter $I$ is used to identify myself, the interviewer. Further discussion on each participant's story is included in Chapter 6.

\section{Alex.}

Alex presented four higher-order themes in the in-depth interview: social relationships; an inner search; connectivity and revitalization; and skill development. Below is the narrative from the interview.

\section{'This solidifies my understandings [of people and places] to a certain extent'.}

Alex grew up on the west coast and spent a lot of time either on boats or in the water. The area around Hooksum Outdoor School also had familial significance for her, and Alex had many memories of spending time in and around the Pacific Ocean with friends and family. As someone 
who spends a large amount of time engaging with water, the connection between social relationships and the physical west coast emerged throughout the interview. In the following extract, Alex was asked to elaborate on one experience that stood out during Hooksum:

The closeness between me and people I don't even know, is really one thing that's pretty astonishing... how everybody, even though we're different, we come from totally different places, we're all here for the same reasons.

Developing relationships with people was a major element throughout Alex's experiences. In the following extract, she was asked if there are things or interactions that help make the close group dynamics personally significant:

Getting to hang out with people one-on-one, you know? Being in groups, like, for kayaking and for lifesaving... really brought me closer to people in my groups, we had such a good time. And you get to see the side of people that you probably never would see in different settings.

The impact of social relationships also influenced a lot of the ways in which Alex identified as being different since the start of the program. The following two extracts highlight these elements. In the first, Alex explained why these experiences (closeness with the group) are important. In the second, she talked about being different since starting the program:

The course has just been so fun, with new people I've met and hung out with. The things we've all done together as a team and individually. Ah... it really kind of shows how you can... pluck people from all over, put them together, and they can pretty much work things out.

Um... intellectually, I'm more one with the universe. Actually, I honestly feel like before I came up here, I had been getting a lot into doing yoga, sitting just by myself beside the ocean and taking the energies from everything. Understanding people and places, and this sort of solidifies my understandings to a certain extent. 
When asked to elaborate a bit more on these understandings, Alex mentioned the chance to sort out thoughts, think, and feel without distractions. A point of interest in these extracts is that coastal environments held a strong social significance to her. Whether it is from growing up and spending time with family on the coast, or spending time with friends and group members at Hooksum Outdoor School, it is possible that the coast was intertwined with social relationships to Alex:

\section{'I needed to get away from the city, kind of find myself I guess'.}

Coming to this coastal environment was part of an inner search for Alex: searching for who she was, needing time to sort out thoughts, having life experiences, and coming back to what Alex thought was important in life. The following extract presented this search:

Just seemed like a great idea, you know. And needed to get away from the city. Kind of come back to real human roots. Kind of find myself, I guess. Again. And it comes along with meeting great people, and I'm gonna have friendships probably for the rest of my life.

A key factor in this inner search was having the space without any distractions to sort out thoughts, feelings and gain personal direction. The first extract below includes Alex's explanation of what helped facilitate "stand out" experiences. In the second, Alex described inner change (a change in a change in how she thinks, feels or sees herself in the world) during the program:

A: Just, hanging out with people, with no other distractions.

I: So kind of like, the uninterrupted time with people, you would say?

A: Yeah man (pause). No television or music, cars going by...

A: Uh, yea. I definitely have felt, um, very big inner change. You know, I feel myself just being myself again. And seeing things clearly. Rather than, 'Oh my god what am I doing with my life?' and sort of, nudged back into the right direction. 
Alex saw the natural environment surrounding Hooksum as something that could assist in the inner search. Being in a quiet environment that is not busy or distracting with city noise was what Alex saw as key features to help feel like herself. Being by the ocean allowed Alex to feel at peace and like she was "normal again". This could suggest that Alex came to this particular coastal environment in order to come back to her true self and that Alex's true self is linked with the natural environment.

\section{'It [the ocean] actually gives me a lot of energy'.}

The beauty of the coast is something Alex found breathtaking; she recognized the natural beauty and at the same time, experienced an increase in energy levels. When asked to describe experiences she was having, Alex vocalized the ocean's beauty in the following extract: "Being out in a kayak, you know, lifesaving. The coast itself is beautiful out here, it's breath taking."

Not only did Alex find the coast beautiful, but there was also a personal feeling of need when it came to the ocean. Alex felt the need to be near the ocean, either because of its beauty or its revitalizing effects. In the following extract, Alex answered what her experiences at Hooksum meant personally:

I feel this has been a life-changing course for me. Honestly, I want to go back... start doing something with my life... I want to be by the ocean wherever I go. I don't think I could be anywhere without the ocean with me.

The beauty of the coast was also an interactive experience for Alex, as she saw the ocean as something that gave her energy and revitalization. There was also an indescribable sensation when thinking about the ocean for Alex:

I think, actually, it's a bit of love and no hate relationship. It actually gives me a lot of energy. And, you know, if you're tired you jump in it. Gives you life back. But if you're in all day, it'll put you to sleep. Um, I don't know, it's fresh air. And great sunsets and 
sunrises. I don't know, I love the ocean (pause). It's almost indescribable. How I feel about the ocean...it's always there. It's there for me.

This energy also gave Alex comfort during sad points in life, happy memories and amazing sights, as well as an understanding of the ocean's power and mystery. Alex elaborated on her relationship with the ocean:

In my saddest times in life, I've gone to the ocean and got comfort. Even though you get it from friends and family, it's a little different. And the happiest times. Some of the most amazing things you can see, I have ever seen, have happened on the ocean...it's just, like, the power behind the ocean. And what we don't know (pause). It's pretty amazing.

Receiving energy and comfort from the ocean also helped facilitate Alex gaining a sense of clarity during the program as well as a sense of belonging and purpose. The inner change Alex experienced allowed her to "think properly" and the environment helped facilitate that change. In the following extract, Alex was asked how the place helped with inner change: "It just feels, like, almost like where I'm supposed to be, you know?"

Participating in the Hooksum program gave Alex clarity, a sense of belonging, and the chance to be in an environment that was beautiful, mysterious, indescribable, and something to feed off of and become revitalized. Alex's perception that being near the coast is necessary could suggest feelings of connection or that she had a desire to build a deeper relationship with coastal environments.

'I wanna base my job somewhere around the ocean, honestly'.

Alex was also interested in training and the education. Though not the major factor behind Alex's reasons for signing up for the program, she was interested in skill development in order to be able to live and work near the ocean. The coursework and learning was exciting for Alex and provided valuable knowledge to take back home. "It's all towards a lot of stuff that I 
want to do. I wanna base my job somewhere around the ocean, honestly. And have a good time while doing it."

Key points are that Alex saw the coast as a professional opportunity but the idea of an ocean-based job dis not stop at the professional level. It could suggest a desire for meaningful work or a lifestyle with which Alex had a personal connection. Choosing an outdoor and oceanbased profession could have connections to the above higher-order themes of social relationships in coastal environments, inner searching facilitated by the environment, and connectivity and revitalization.

\section{Elijah.}

Elijah presented four higher-order themes in the in-depth interview: relationshipbuilding; lifestyle application; emotional change; and feelings of attachment. Below is the narrative from the interview.

\section{'I just lost touch with the ocean'.}

When Elijah was a child, he spent a lot of time in the water and near the ocean. He also had a near-drowning experience when young, resulting in a fear of dark water. As an adult, Elijah mentioned that he didn't spend a lot of time in the water leading up to the program, although he often was near water, walking along the beach, and would go in the water up to his toes. The following extract included Elijah's response when asked if he spends time near the Pacific Ocean, which is the closest body of water to his home. The second extract summarized the difference between how often Elijah spent time near water as a child and as an adult:

As much as possible, but I never really get the time. But, I know for sure that I will be spending a lot more time there since I've been here at Hooksum. 
I never really had a relationship with the ocean, except when I was a kid. When I was a kid, the summertime I would just play in the ocean pretty much every day or every other day. And then, once I finished being a kid I pretty much went into being an adult.

Hooksum helped Elijah develop a relationship with the ocean and the motivation to spend more time in the water when he returned home. A key feature of this was learning to surf; in the next extract, Elijah elaborated on his relationship with the ocean:

E: Now? I kind of regret growing up so fast that I just lost touch with the ocean, because it's so beautiful.

I: Would you say you have a relationship with the ocean now?

E: Definitely have one (pause). It was funny last night, just before I was gonna crash out, I (chuckles) I was thinking to myself, 'I wonder how big the waves will be at five in the morning'? (Laughs). Trying to decide whether or not I could surf that early. Even though yesterday was only my second time learning how to surf.

The key point of interest here is that Elijah was developing a relationship with the ocean by participating in the Hooksum program, and surfing was one of the major factors that helped facilitate this relationship. Because Elijah referred to surfing as being an essential activity in helping to develop a relationship with the ocean, it is possible that without the surfing experience, Elijah's relationship-building would have be quite different.

\section{'I can bring these experiences back home'.}

Though Elijah agreed the certifications were a motivating factor in attending Hooksum, he claimed that wasn't the major reason for signing up for the program; he was more interested in having the experience. For Elijah, learning skills provided the chance to develop a lifestyle that could be taken back home after the program. Elijah explained the reasons he signed up for the program: "For the experience. And um (thinks) to get away from civilization. And, yeah, certifications. But most of all the experience." 
Elijah saw the experience as something that could be taken back home to his community as an alternative to the television and video game culture. He wanted to take the healthy lifestyle back in order to inspire others in his community who drink and are not active, and that gave a lot of personal meaning to what Elijah was experiencing during the program. This program also inspired him to live in the 'wilderness' like the owners of Hooksum Outdoor School. Elijah explained how he would like to live like the owners of the program: "I think I would like to live away from civilization like them (pause). Probably with my family like them."

A key point of interest in all of these extracts is that Elijah's motivations had to do more with lifestyle application as opposed to qualifications or a career. This could imply that Elijah saw ocean-based certifications as a way of life, rather than simply a profession, and could contribute to seeing this program as something that can have personal significance and be integrated into his community.

\section{'I've changed emotionally'.}

Elijah had a traumatic experience in water as a child, and participating in the kayaking and lifesaving courses brought up childhood flashbacks. A major significant experience, however, was overcoming his fear of dark water during the program. In the following extract, Elijah was asked to elaborate on one experience that stood out during the program:

One experience... when we were doing the kayak courses, was (thinks, sighs), I had a flashback that made me realize and remember that I'm afraid of dark water... I quickly overcame that fear... actually it was the very last day of the lifesaving course, which followed the kayak course.

Overcoming this fear contributed to an emotional change in Elijah, and in the following extract he talked about how he felt about overcoming his fear: "Exhilarating. Really good. Felt like, oh I don't know, a feeling of success. Some sort of power I guess." 
Elijah also vocalized that he was undergoing an inner change during the program, although he could not describe what the inner change was more specifically. He did mention examples of emotional changes he had been experiencing throughout the program. His anxiety was mentioned in the following extract:

I: In what way do you think you think you might be different? Physically, mentally, emotionally, spiritually, or any other ' $l y$ ' (both chuckle)?

E: Um (thinks). Probably physically, but it doesn't really feel like I have...I've really changed. Maybe mentally, too.

I: Can you elaborate a bit on the mentally part?

E: Um, actually, emotionally, I'm pretty sure I've changed emotionally.

I: Yeah?

E: On the mentally part?

I: Or on the emotional part.

E: On the emotional part.

I: Up to you.

E: I'm experiencing less anxiety since I've left home. (pause) I... (pause)

I: You mean, since you've left home and come here?

E: Yeah. And it seems as the days come for us to go back home, that anxiety is coming back.

In addition to anxiety levels being affected during the program, Elijah also mentioned feeling more relaxed in the environment. He elaborated on one element that he finds relaxing: "Just falling asleep to the sound of the waves every night. It's so soothing."

Elijah identified as having experienced emotional changes during the program, and the ocean has stood out to him when he discussed his emotional change, either through overcoming a fear of water or by providing soothing sounds to reduce anxiety. This could imply that the coastal environment had a key role to play in Elijah's emotional changes.

\section{'I'm gonna grab a piece of every beach along the coast'.}


Elijah had respect for the experiences he was having near the water, thinking that they represented 'pure' experiences. When discussing what he would take back home from the program, Elijah mentioned the beach:

Well, mental image. And pieces of the beach. Since I've been here I've realized that not every beach is the same on the coast. So there's a few things that I'm going to take back home with me....seashells and rocks...actually, I'm going to probably grab a piece of every beach along the coast.

At the end of the interview, Elijah said he didn't want to leave. This, coupled with collecting pieces of every beach, could imply an attachment to the beach, and could suggest relationship-building occurred between Elijah and the ocean. If this is the case, object collection could symbolize this attachment or a token for passing emotional hurdles (and is mentioned again in the Chapter 5). The higher-order themes of relationship-building, lifestyle application, emotional changes and feelings of attachment all suggest that Elijah's connection to the ocean greatly increased throughout the program.

\section{Morgan.}

Morgan presented four higher-order themes in the in-depth interview: feeling privileged; professional development; the value of living by water; and euphoric sensations. Below is the narrative from the interview.

\section{'I can imagine this is a very special place'.}

For Morgan, favourite childhood memories included spending time in the ocean and by water, although these memories were often seen as special "treats" or family outings. The idea of the ocean being a special treat or privilege was a theme that came up throughout the interview. In the following extract, Morgan reflected on childhood experiences with the ocean:

Most of the time, because I lived in cities, it would be something depending on the 
weather. And also as a treat, so mainly, you know, weekends, a family outing...just all relative to how close I was to the water. The closer I am the more I visited.

These memories carried significance associated with a special family occasion. Morgan reflected on beachcombing with brothers and awaiting the mysterious treasuries that would wash up along the shore:

We were always collecting animals, and insects, that was our most fascinating thing. It's funny, but we still do it to this day... collecting whatever we find under the logs. And so the ocean for us was amazing... I'd be sitting there combing the beach on my hands and knees for hours and hours on end.

The idea that the beach was for special occasions helped shape Morgan's feelings on coastal environments and his recognition of the ocean's value. In the following extract, he was asked to explain how he felt about being in the coastal environment at Hooksum:

Ah...very privileged, to be honest. Privileged to have the opportunity and the chance to be here and live here. So very fortunate. And fortunate in a sense that... it could be that I believe that there isn't many or much of this left...I can imagine that this is a very special place.

Morgan recognized the uniqueness of coastal environments and the beauty associated with these surroundings, and this recognition largely influenced Morgan's Hooksum experience. The environment was viewed as something special and of valuable significance. Although these are values Morgan had before entering the program, these experiences seemed to generate a feeling of renewed affirmation.

\section{'It's all reinforcement for the future'.}

Morgan has a desire to work in the outdoor education field and was taking the Hooksum program as a way to develop the skills required to move into that career path. Setting up for a future career shaped how Morgan viewed experiences; a major theme was the program's 
applicability to future goals. In the first extract, Morgan explained the reasons for signing up for Hooksum. In the second, Morgan was asked if those reasons are different since starting the program, and the answer included a reflection on confidence:

I'm looking to get certified in, well numerous different areas. Mainly the wilderness first aid. So that I can pursue a career in the outdoor therapeutic industry... I knew that I needed these pre-requisites to get involved.

As far as gaining confidence that's definite through having succeeded in passing most of the exams, well, all the exams currently. So it's all reinforcement for the future... and that's a great feeling.

Morgan also gained confidence through the group dynamic and structure. By being in an outdoor environment like Hooksum, Morgan noticed that the group dynamic allowed him to gauge himself, recognize his own attributes, and confirm what he was able to give or provide to others. This idea of gauging helped to develop confidence in what Morgan could provide to group members and what he was proud of as his skills. In the following extract this thought is elaborated:

The thing that's great about here is we've found such a range of different age groups, range of different experiences, range of different cultures, backgrounds. So initially it's hard to know where you do stand. But when we are all put in a situation that is new to us, and to have to sleep in a remote place like we did yesterday, it kind of does reveal and show where certain roles seem to appear. And it's really pleasant to know, 'Oh, I'm good at this. How about I do this'.

This confidence confirmed to Morgan that he was headed down the right path. By actively engaging with the environment through the courses, skill training and group members, Morgan was able to reaffirm that a career in the outdoors was an appropriate choice. This confidence was a great feeling for Morgan. 


\section{'It's always been my favourite place to be'.}

Morgan is a person who has always loved nature and enjoyed being outdoors. The ocean provided great memories, and the chance to experience the natural beauty was something Morgan appreciated. The following extract demonstrated the value Morgan placed on living by the water:

Being fortunate enough to have these experiences near the water or in the water, and always knowing that, you know, that's some of my favourite memories. I could always think to myself, 'you know, I hope I can live by the ocean, someday, somehow'.

The value that Morgan saw in living by the ocean stems from his relationship to the ocean and the personal value that as been placed on coastal environments since childhood. The enjoyment and positive feelings associated with spending time near water has largely influenced Morgan's relationship with the ocean. This relationship was stated simply and accurately in the following extract:

I: What is your relationship with the ocean?

M: It's always been... my favourite place to be.

When asked if Morgan experienced inner change during the program, there was skepticism if what was occurring was in fact change, or rather a confirmation that living on the beach was important and his future career goals were on the right path. In recognizing a personal need to live by water, Morgan accepted that there is a benefit to living by the ocean that satisfies, gives fulfillment, and provides focus and clarity that could not be gained in a different environment. This recognition contributed to a feeling that the ocean was a "favourite place":

The actual creative output for me as an artist, living in these circumstances or living in the wild, it gives you a lot of focus and clarity, which you would most likely not have if you didn't have this experience. 
Morgan saw many benefits to living by the ocean. The positive feelings from childhood through to adult, and the focus gained by being in nature, allowed Morgan to accept that living in coastal environments is important. This lifestyle was a goal that Morgan wanted to continue after the program. It is possible that the experiences at Hooksum influenced a confidence in Morgan and without participating in program, he may not have developed the assurance in making this lifestyle goal.

\section{'[The sensation is], kind of, well, euphoric'.}

A prominent experience for Morgan was an endorphin-releasing sensation when in or on the water for extended periods of time. This sensation came often throughout the program and was a feeling Morgan found to be significant. Morgan first mentioned this in the interview when asked to explain some experiences he was having at Hooksum:

Um, well, just recently starting to realize after long sessions spent either swimming or kayaking, so actually being in the water, I have started to realize that there's a, maybe endorphin-related kind of high after the activities...I'm not alone as well...another has also noticed it. And I can see the effects on other people.

When asked to elaborate on this "high" and explain the sensations, Morgan presented the following explanation:

Well to be honest, the actual effect is almost exactly the same. It doesn't really vary in intensity or anything like that. They all seem to carry a similar, well almost exactly the same, yeah, the same sensation....so it would be like, I don't know, kind of euphoric. But also an incredible sense of calm as well. And, almost like a connection to something else. Something innate that's been exercised...it's very, um, extremely pleasant.

When asked if any things or interactions helped to facilitate these experiences, Morgan suggested the opportunity to live on the beach and to be constantly near the ocean could have help make these sensations stand out: 
I think, just the opportunity to actually live on the beach. So, actually, always having a connection with the ocean. It's, ah, you know the perpetual waves constantly being heard. Even when your mind isn't actually focusing on them. But you can also feel it, you know, and they do, they're thundering all through the night. You can almost feel it through the stones.

When taking about this euphoric sensation, Morgan felt that it represented a connection between something in an individual (or simply himself) and the water. In the interview, it was compared to a drug-related experience, and Morgan wasn't sure if it was because of the water itself or living by the water. He thought the sensation could still appear if someone went to the beach for one day and spent hours in the ocean. Morgan also referred to it as "bliss," but explained that it was something he couldn't specifically pinpoint or label. It was also comparable to an addiction or feelings of being free.

The experiences aren't, it's a lot like a drug-related experience or sensation. It almost feels like something that is quite real and natural. It isn't chemically enhanced or artificial in any way...just thinking about it now, logically, you know, there's a reason surfers are absolutely addicted to the ocean. And I swim to simply feel like I'm in the ocean. More free... it just feels correct within myself...it seems to make sense.

For Morgan, this sensation was uniquely tied to water, as opposed to other natural environments. Though he was a person who loves all natural environments, Morgan explained that the effect was stronger with the ocean: "It's a sensation that you can't really get from anywhere else. Not in its purest form...it's a difficult one to put into words, to be honest. It is what it is."

This sensation was indescribable to Morgan, but held deep value and significance. Morgan recognized an emotional trigger by being in the water and could only compare it to highs or euphoria. It is clear that Morgan's energy and feelings were deeply tied to the coastal 
environment, and by actively engaging in the water a shift in sensation or energy was heightened.

\section{Quinn.}

Quinn presented four higher-order themes in the in-depth interview: group closeness and familial reflections; authentic education models; emotional change; and curiosity and feeling humbled.

\section{'We have a special relationship'.}

When discussing reasons behind signing up for the Hooksum program, Quinn reflected on an existing connection to this particular coastline and the personal significance of the ocean with regards to family. As a person who spent a lot of time near water, either by walking, meditating, and spending time with family members, Quinn's personal relationship to the ocean has been largely influenced by a family whose lifestyle has been based around the ocean, had positive experiences in the water, and suffered personal loss connected to the coast. In this extract, Quinn was asked to describe their relationship to the ocean:

With the ocean? Holy, my father was a fisherman, and we built the boat when I was in grade three... needless to say... our boat, um, sunk up here... he was, um, he drowned of hypothermia. He got hypothermia... so, um... that's my relationship. He was a commercial fisherman but all of his- all of my ancestors on my dad's side were all boat builders... so, all our people, we have a special relationship.

Quinn's sense of family and connection to the area was also highlighted when commenting on the positive group dynamics at Hooksum, and how participants sparked reminders of family members back home. This familial atmosphere stood out for Quinn: I: How have you felt about spending time here in this coastal environment? Q: Not isolated like I thought I would... I thought that I'd be, you know, I mean, there's been a couple of times where I was particularly homesick... but not as much as I thought 
I would... I'm not feeling isolated, I feel (thinks) yeah. I feel great.

The following extract was in reference to Quinn's perception of inner change during this program:

You know in a small community like this, you don't really have very many places to go (laughs). There's not a lot of privacy. So, um, I guess in a way that makes you, ah, less inhibited. And then you form relationships faster. Conversations develop into really, you know... being around people that are, I don't know, just coming from a place that's really genuine I guess, and honest. And you can trust-you know, all the trust-building we do, you have to rely on people and trust people in a place like this... so I guess maybe thinking about people and just really getting away from judging.

A key point of interest from these two extracts is that Quinn intertwined ocean and family, and applied this familial atmosphere or closeness with group members to "stand out" pieces of the program. It is possible that participant relationships and familial dynamics helped to ease feelings of homesickness, although Quinn couldn't pinpoint why feelings of isolation weren't as strong as expected.

\section{'A reflection of what you see outside'.}

Quinn had a strong interest in learning more about this particular part of the west coast, teachings from the land, and skill development. The following extract vocalized some of the reasoning for signing up for the program:

I'm a believer in teaching from the land. And I've said that in interviews, but I feel kind of fake in saying that, because it's not what I actually do in my day-to-day life. So I think this is a good way to evolve into a person that doesn't just say that I believe that, but that actually practices it as well (sighs). Yeah. So hopefully I can take things like the skills away... to develop more. 
When asked to explain experiences Quinn was having during the program, the first thoughts that came up were about kayaking and wilderness first aid, in addition to how these courses could be applied to daily life or a career back home:

Today we went out kayaking... I've never had a trade, and I've been trying to soul-search about what my trade could be, but this feels like it's right up my alley. You know, I mean I'm going to have to work at it... but I've kind of determined that as long as I apply these things immediately, I can probably build a new career... the first aid course about just different health issues... identifying more specifically how we can be safer... better care of ourselves.

After describing a few experiences, Quinn was given the chance to elaborate on one experience that stood out. Here, the theme of skill development and teachings emerged again, as the instructors were brought up as integrating authentic knowledge and teachings in the educational model. When asked if anything helped facilitate these authentic teachings standing out, Quinn explained some thoughts in the following extract:

I: Are there any things or interactions that have helped facilitate this experience standing out for you?

Q: Um, just that it's a reflection of what you see outside... it's a multi-sensory experience of seeing and doing and hearing and really knowing that it's actually there.

The hands-on and authentic learning model was something that Quinn enjoyed and respected throughout the Hooksum program. A point of interest was that when asked about the personal meaning of these experiences, Quinn responded that she liked that while doing work during the program, it didn't feel like work. This supports Quinn's idea of viewing the outdoor learning and training at Hooksum as authentic, something that involved fun activities like kayaking, and courses that could lead to a possible career in the outdoors. The fact that work didn't feel like work and authentic teachings were directly reflected in what Quinn saw, could 
also imply possible relationship-building with the natural environment, making learning more enjoyable.

\section{'It's like rebuilding'.}

Quinn had personal as well as professional reasons for taking the program. A lot of the personal reasoning stemmed from a desire to seek clarity, retreat from stress or nurture emotional changes. "I needed to retreat from my daily life and a stressful situation (pause)...I guess you could call it a period of change? So, I've just come to solidify my plan of action."

When reflecting on some experiences that were taking place, Quinn noted feelings of being grounded, more emotionally secure, and discussing the experiences at Hooksum caused Quinn to reflect on stressful situations at home and personal hardships. Rather than speaking of these in a negative sense, Quinn noted that being at Hooksum Outdoor School provided memories to hold onto when at home: "Just knowing this peaceful place exists... when I do go out to meditate, if I'm really frustrated and down, I think this place will be a good place to meditate on."

The idea of rebuilding was significant for Quinn, whether it was through reminders of not getting tangled up in stressful things, finding meaning that can be place in small tasks, like helping a group member, or rebuilding a vision for after the program. The following extract presented Quinn's thoughts on making meaning from her experiences during the Hooksum program:

Q: Doing work that's small, like, I don't know, helping somebody with an injury or helping someone get something to drink...small things, right...being sensitive to the needs of others, and helping them the best way you could (pause). Yeah that's one big thing... keeping yourself busy with things that are not such a high priority. And that's what I get tangled up in and stressed out over. In the city.

I: So, being here is a reminder to kind of, not get tangled up in that stuff? Q: Yeah. 
I: And see what it all, what sort of...

Q: Really matters.

I: ...our life meaning is, what really matters is the small things and helping people.

Would you say that's...

Q: Yeah, yeah. Small things. And taking your time about it. And being quiet and humble about it.

When asked if the experiences Quinn was having were personally important, she said yes, and mentioned the program helped instil the belief that small things can be done to make a difference in daily life back home. The follow extract elaborated on Quinn's emotional change during the program:

I: It sounds like these experiences have been really motivating.

Q: Yeah, that's the word! Motivating... at least I have a model now to go, 'ok, on a dayto-day life these things should be done'. And not make it a hardship, or you know, a sluggish ordeal (laughs). So yeah.

I: Do you think you are different now since starting the program?

Q: Yeah.

I: In what ways (physically, mentally, emotionally, spiritually, or other ways)?

Q: Um, just happier. Just more contented. Willing to accept challenges...if I have hurdles to go over, I just go over them and not dwell on them so much.

I: It sounds like you're saying you're different in a lot of, kind of, emotional and mental ways, just being stronger and challenging yourself, and being able to accept challenges. Q: Yeah. Being able to accept challenges, um.... being able to forgive myself. And (pause) you know, for any mistakes that caused me to be in a troublesome spot. And try to envelope myself with more people like the people I met here (pause). Yes, it's like rebuilding. I definitely feel different.

A key point of interest in these extracts is that Quinn was feeding off of the energy from the group and the place in order to take positive energy back home after the program. Two of the things mentioned when asked if there was anything Quinn would take home from Hooksum 
Outdoor School were energy and confidence. This could imply that both the group and the environment were beneficial and revitalizing for Quinn, and personal energy was connected with the environment at Hooksum in order to feel rejuvenated.

\section{'It [the ocean] has more to teach us than meets the eye'.}

Quinn vocalized feelings of curiosity and being humbled by coastal environments. When explaining a desire for professional development, Quinn hoped for confidence both in skill training and in having intention when spending time in or near water:

Q: I know I go there, but there's something missing, there's a hole missing in going there. So yeah there's something more I can be doing than just walking through...or running. Those are the things that everybody does. And it just seems like there's something deeper that can arrive when you go to places that are really special. So, yeah...

I: So you're looking to find what that is.

Q: What it is, yeah.

Quinn recognized that there is something almost indescribable about the ocean that demands a sense of respect. Being asked about experiences she was having at Hooksum drew out feelings that the ocean is full of mystery, power, and something that should be respected. In the following extract, she explained this sense of mystery:

Q: I could go on and on for days about the ocean and how much wonder I have for it. Like this octopus...they can camouflage themselves to be exactly like that [sleeping bag]...they can just imitate the colour...I'm just like, 'wow', you know? There's so much that we don't know... so there's just so much mystery under the see. God, I love that. I: You love the mystery about the ocean?

Q: Yeah, I love the mystery. And I love the freshness of the...it's like this abundance. To me it's a symbol of abundance. Of everything...it nurtures us, it smells good, it's visually...changeable. It's changeable and unpredictable, and you could study about it for your whole life, like one little corner of it (chuckles). Yeah...I feel like I know it. And yet I know I don't know it (laughs). 
These feelings of wonder and curiosity are offset by a sense of humbleness. Having grown up by the ocean in addition to losing loved ones at sea, Quinn's respect for the ocean ranvery deep emotionally. Quinn vocalized feeling like people don't respect the ocean enough, and when prompted on this idea, Quinn responded in the following extract:

I: Would you say you respect it?

Q: I would say I respect it... I don't think people... I don't think everybody gets it. Yeah. And I think it has more to teach us than meets the eye.

The higher-order themes from Quinn's narrative show a sense of closeness with group members and familial reflections, hands-on and authentic education models, an emotional change during the program, and feelings of curiosity for and being humbled by the ocean. Quinn also collected shells to take home as gifts or tokens from the surrounding coastal environment. 
"I've rode on top of killer whales while they're rubbing up to the side of the boat and forty other killer whales around me. And I've seen them teach their young how to hunt, throw it around, but then put the sea lion back. I've seen humpback whales breeching twenty metres away, twenty feet away, being heart-pumping while everybody's taking pictures like (chuckles), like it's a normal, everyday thing”. 


\section{Chapter 5: Discussion}

The findings of this study have shown that for participants at Hooksum Outdoor School, emotional relationship-building occurs when being in coastal environments with direct contact with the ocean. In this chapter, I discuss how outdoor adventure training acted as a major factor in two forms of emotional change: (a) participants as active beings organizing their worlds and (b) participants experiencing events through unique lifeworlds. I will then discuss what these claims mean in regards to the biophilia tendency, attachment, and a sense of place.

\section{Active Beings Organizing Their Worlds}

In exploring the research findings, it is obvious that participants were active individuals who were attempting to organize the world around them. The theory that human beings seek out stimuli instead of waiting for stimuli to move them into action is widely accepted in phenomenological research (Combs \& Snygg, 1959, as cited in Patterson, 1965). What is unique to this study, however, is that each participant's actions assisted in developing emotional relationships with the coastal environment. Participants came to the program in pursuit of clarity, intention, or focus, and thus, behaved as active beings. They sought out stimulus while in a coastal environment and transformed what was received into plans for personal and professional action.

Outdoor adventure training acted as stimulus for each participant. Through kayaking, surfing, or swimming in the lifesaving course, participants became more than empty vessels that would receive energy, positive skills, or feelings of relaxation and then carry on with their days. Participants' active processes involved a cognitive organizing of how the events at Hooksum fit into each individual's world, followed by making meaning out of each activity (e.g., Quinn discovering a career path in the kayaking course). I believe organizing and making meaning of an individual's world is one of the foundations of relationship-building. Relationships are only as 
strong as the meaning an individual places on them. The organization of these meanings is constantly changing, altering the way in which we form and develop relationships. For example, Elijah's fear of dark water stemmed from an event that had an associated negative or fearful meaning. This contributed to him not having a positive relationship with the ocean, if any at all. Years later, the act of surfing had an associated positive meaning for Elijah, and his relationship with the ocean shifted in order to reflect this new meaning.

What can be said, then, is that outdoor adventure training can provide a stimulus to assist individuals who are attempting to organize their own worlds, and may become a catalyst for meaning making that can largely influence the relationships humans have with their environments.

\section{Experiencing Through Lifeworlds}

The findings from this study confirm that all four participants experienced the Hooksum program through their own lifeworld. The concept of a lifeworld is prominent in phenomenological psychology. Eatough and Smith (2006) define the term as the subjective experiences of the individual. Combs and Snygg (1959) use the term phenomenal field, which addresses the same concept (as cited in Patterson, 1965). Lifeworlds are unique to each individual, consisting of familiar beliefs and past experiences that influence how events are interpreted (Brewer, 2003).

It was difficult for participants to discuss their experiences at Hooksum without drawing on past beliefs or experiences pertaining to the ocean or water. They vocalized their experiences through their own subjective lifeworlds, a way in which they viewed the world, which were riddled with familial meanings and associations. Participants sharing their lifeworlds with me made experiences unique to each individual, and each expression of feelings and emotions became an authentic representation of the individual and how they saw themselves in the world. 
The idea of a lifeworld is not new in research, however, in this study, outdoor adventure training facilitated authentic and meaningful experiences by highlighting each components of each lifeworld. Participants did express common responses and behaviours at Hooksum, but aspects of the program were experienced differently through each individual lifeworld. The lifesaving course provided a chance to bond with group members for Alex, an opportunity to overcome fear of dark water for Elijah, and a chance to swim in the ocean and feel free for Morgan. Without having the framework of outdoor adventure training, it would be near impossible to fully recognize each authentic experience. This is due to the fact that ocean-based lifesaving can be seen as a common denominator for each individual, and the uniqueness of each experience is contrasted with this common activity.

Outdoor adventure training is invaluable for viewing contrasting lifeworlds: surfing, kayaking, and coastal first aid all provide standard rules and skills for each participant to master. Waves and weather conditions are experienced together so the differences in meaning making become much more apparent than if participants were exploring the coast on their own free time, outside of a standard training process. By recognizing each individual's authentic lifeworld, it is possible to see cognitive and emotional changes participants experienced during Hooksum Outdoor School.

In a study of the effectiveness and outcomes of outdoor adventure training programs, Hattie et al. (1997) found that major benefits include self-understanding, regulation of self, and self-assurance. Self-understanding emerged in this study's individual interviews, in addition to the idea of gauging oneself in a group environment, and participant confidence or feeling an assurance of self. This study confirmed that during the Hooksum program, participants experienced through individualized lifeworlds and actively organized the events of their world. It has also shown that participants develop emotional relationships with coastal environments 
through engaging in outdoor adventure training. What can be suggested, then, is that outdoor adventure training stimulated self-understanding, self-regulation, and self-assurance in these participants, which are beneficial characteristics for healthy relationships. These inner cultivations helped positive relationship-building at Hooksum Outdoor School.

\section{What does this mean for Biophilia?}

Participants' active organizing of experiences through outdoor adventure training demonstrated emotional relationship-building. Specifically, individuals expressed their relationships in four of Kellert's (1993) unique, biophilic ways: naturalistically, aesthetically, symbolically, and humanistically. Engaging in the coastal environment and participating in training activities seemed to heighten each of these dimensions of the biophilia tendency.

The naturalistic dimension of biophilia is described as "encompassing a sense of fascination, wonder, and awe derived from an intimate experience of nature's diversity and complexity" (Kellert, 1993, p. 45). Similarly, the aesthetic dimension includes, "feelings of awe at the extraordinary physical appeal and beauty of the natural world" (Kellert, 1993, p. 49). The findings show that all participants expressed these behaviours throughout the program. Quinn's sense of wonder for, and being humbled by, the ocean and its mystery suggest a sense of curiosity for the natural world. Alex noting the coast as "breathtaking" and Elijah finding the waves soothing could suggest feelings of awe and serenity. Morgan's euphoric sensation in the water was also described as bringing an incredible sense of calm. These behaviours suggest that relationship-building (either building a new relationship or building upon an existing one) was occurring on a naturalistic and aesthetic level, thus activating two dimensions of a biophilia tendency.

Object collection suggests a sense of attachment to the environment, and a symbol of participant memories and experiences at Hooksum. Collection can be seen as a demonstration of 
what Kellert (1993) calls the symbolic dimension: that is, using nature a means for communication. He notes that throughout history, humankind has used nature as a way to communicate lessons or metaphors through stories, songs, or art. Participants at Hooksum exhibited behaviors that may be linked to the need to surround oneself with nature and objects from the outdoors.

On a similar note, Morgan's inspiration as an artist was strongly linked to the coastal environment. By gaining focus and clarity that couldn't be achieved in another environment, Morgan used the coast as a means to generate music. Relationships with nature became activated on a symbolic level, increasing another dimension of the biophilia tendency.

\section{Humanistic Biophilia and Attachment for Environments}

Participants also expressed behaviours linked to Kellert's (1993) humanistic dimension; that is, "deep emotional attachment to individual elements of the natural environment" (p. 52). Quinn understood that there is something deeper to be found from the water, and although unable to pinpoint it, seeks more intention when in or near water. This may suggest an attachment to the coast. Alex felt a strong need to live near the ocean, Elijah experienced emotional changes and was determined to take home a piece from every beach, and Morgan swam to feel connected and a part of the ocean.

Feelings of attachment for the natural environment were strengthened with bursts of positive energy that were activated through kayaking, swimming, and surfing. These feelings were directly linked to an individual's ability to be in or on the water during the program. Overcast weather did not affect participant moods if they were still able to surf or kayak. Multiple participants attributed being on the water as the "best" parts of the day, or reflected on a feeling of euphoria or a "stoned" state that continued when they came out of the ocean.

What this suggests is that outdoor adventure training activated an energy release that was 
beneficial in facilitating bonding with the natural environment. I believe that in many relationships that humans develop with other individuals, experiences that release positive sensations or energy boosts can contribute to a feeling of attachment for, or a bond to the other person. In the same way, engaging in activities that released euphoric sensations and positive associations seemed to be a factor in developing a bond with the coastal environment at Hooksum. It is possible that individual feelings of attachment become stronger when associated with a boost in energy.

It is interesting to me that participants expressed behaviours linked to four of Kellert's (1993) nine dimensions of the biophilia tendency, but outdoor adventure training was a major factor in allowing this tendency to be cultivated and stimulated, as discussed earlier. Feelings of awe and wonder at the environment's natural beauty were heightened through technical skill development. Without strong paddling or swimming skills, breathtaking views and wildlife spotting would have been inaccessible. In addition, positive releases of energy associated with outdoor adventure training seemed to strengthen feelings of bonding and attachment to the natural environment.

\section{Place for Biophilia}

It is evident that participants developed an attachment to the coastal environment at Hooksum Outdoor School, whether through positive memories, inspiration, or object collection. Place attachment and place meaning are the two elements that make up a sense of place in ecopsychology research (Kudryavtsev, Stedman \& Krasny, 2012). A sense of place is an active relationship between an individual and a place, which includes factors such as biology, culture, society, and physical features (Kincheloe et al. (2006), as cited in Kudryavtsev et al., 2012). This concept appears similar to soliphilia, as biophilia is more broadly an affiliation with natural living systems. Participants showed behaviours linked to sense of place and the biophilia 
tendency simultaneously.

Scholars such as Semken and Freeman (2007) claimed, "authentic place-based education is experiential and transdisciplinary" (p. 1044). In this sense, outdoor adventure training can be seen as one variation of place-based education. During outdoor adventure training, participants gained an attachment to the coastal environment at Hooksum and developed a deeper understanding of its history, surroundings, and ecosystems. What is of interest is that participants gained an even greater understanding of themselves and their relationship with the ocean during the program, and these will both be carried back to their home communities. Without deeper psychological research, it is difficult to argue whether elements of a sense of place were being developed for Hooksum Outdoor School's environment, for participants' home environments as they reflected on positive coastal memories, coastal environments in general, or a combination of all the above.

The emotional relationships that individuals cultivated during this study were strongly linked to creating a plan of action after the program, or maintaining and/ or strengthening relationships with coastal environments back home. This poses the question of whether individuals need to be in a particular environment in order to develop a sense of place for it, or if a sense of place can be sparked in one area and carried over to another environment. More specifically, it is important to question if participants have a sense of place, or sense of places. Attachments for the coastal environment at Hooksum fostered relationships with the coast that participants wanted to maintain at home, not all of which are on Vancouver Island. It is possible that by being in this particular coastal environment, participants strengthened relationships specifically with the ocean (as opposed to the full coastal ecosystem), providing an element that can be transferred to different coastal environments. That would suggest that common environmental features (e.g., the ocean at Hooksum Outdoor School) become determining factors 
in how individuals cultivate long-term relationships with the earth. Again, this brings the research back to Kellert's (1993) humanistic dimension of biophilia, which focuses on deep attachment to an individual element of nature.

This study also raises the question of whether humans, either consciously or subconsciously, recognize that all oceans are connected, and if coastal outdoor adventure training allows relationships we cultivate with the ocean to be transferrable to other coastal environments. It is possible that outdoor adventure training activates a sense of place to particular elements of natural environments that can be applied to various places, and within this process is where a humanistic dimension of the biophilia tendency is ignited.

Based on the findings of this study (Elijah an surfing, Quinn and kayaking, and both Alex and Morgan with skill development), outdoor adventure training was essential in cultivating emotional relationships with the coastal environment. The training acted as a catalyst in organizing meaning in individuals' worlds, viewing authentic, contrasting lifeworlds, and creating a sense of attachment to the environment. These relationships have direct connections to four dimensions of the biophilia tendency and are determining factors in developing a sense of place for the environment. 
"I feel very fulfilled. I feel fulfilled." 


\section{Chapter 6: Recommendations and Conclusion}

This study explored four participant experiences at Hooksum Outdoor School on Vancouver Island over a period of 28 days. The research provides a starting point to understanding biophilic relationships with the ocean. Its findings hold value for outdoor education and psychology research, as understanding how outdoor adventure training contributes to a biophilia tendency and emotional relationship-building is essential in moving forward in research and program design. The study was limited to Pacific coastal environments, and although valuable interpretations have been made about this particular phenomena, there exists opportunities for future research to build upon this work. Effective educational program design can also benefit from this study and my recommendations. The following recommendations are grouped into two categories: recommendations for future research, and recommendations for program design.

\section{Recommendations for Future Research}

This study focused specifically on Pacific coastal environments in an effort to ensure that I could conduct immersive and authentic fieldwork. To widen participant sample size and to help determine if the ocean is a key factor in biophilic responses, the methods and tools used in this research could be applied to various immersion outdoor schools in different coastal environments. While the findings of this research confirmed that individuals experienced outdoor adventure training through subjective lifeworlds, it would be possible to search for commonalities between participants in different coastal contexts. Using a phenomenological psychology approach would still maintain the authenticity of each individual's unique experience. Widening the region, either through exploring multiple environments throughout the Pacific or extending to the Atlantic, could provide insight as to whether the emotional relationship-building was unique to Hooksum Outdoor School, or connected to coastal 
environments and engagement with the ocean at large.

The framework for this study could be adapted to examine outdoor enthusiasts who have chosen to live and settle in coastal environments (e.g., surfers or kayak guides). Understanding their daily experiences could provide a deeper analysis for how ocean-based activities affect relationship-building with the environment and influence life choices. This research would veer slightly from examining a phenomenon in a month-long program sense. The phenomena of research would include specific feelings and responses when engaging in or on the water.

Object collection and euphoric sensations are intriguing themes that emerged from participant behaviour and interviews, and provide a springboard into cognitive psychology research. It is possible that participants collected objects for reasons other than finding them interesting or pretty. The need to surround oneself with nature or to place memories on artefacts from the coast could suggest an emotional and cognitive process that is worth investigating. It is possible that when individuals find it difficult to put their relationship with the ocean into words, natural objects are seen as more adequate in communicating emotions than language.

Euphoric sensations also require future research. It is possible that these sensations reflect positive feelings, but to participants, the sensations seemed far deeper than any feeling. Research could explore if a hormonal, chemical or other physiological shift/stimulation is triggered within an individual while in the ocean. The body of research that examines flow, known as the exceptional moments that "provide flashes of intense living" (Csikszentmihalyi, 1997, p. 46), would be beneficial in building further studies.

\section{Recommendations for Program Design}

While adventure education values direct experience and psychological restoration, the focus on its connection with a biophilia tendency is emergent and not widely recognized or adopted in educational program design. As the literature reviewed showed a strong relationship 
between passion for nature and positive environmental behaviours (Orr, 2004; Perkins, 2010; Rowley, 2010; Sobel, 1998), and as outdoor adventure training and coastal environments triggered emotional responses within participants of this study, outdoor adventure education should incorporate biophilia into its design. What is needed is to implement strategies that monitor the biophilia tendency during adventure education. The Pre-post post-program questionnaire used in this study could easily accompany a kayak lesson and shed insight as to whether the biophilia tendency is being triggered.

\section{Conclusions}

This thesis provides opportunities to carry the ideas presented into future research. In order to motivate individuals to engage in conservation efforts, or to design more effective educational programming, we must first understand what people love about the environment, why they love the environment, and how individuals act on their love for the environment. Based on participant observation, 28 days of conversation, interviews, and questionnaires, this study has shown that emotional relationship-building occurs when being in direct contact with the ocean through outdoor adventure training programs. It is my firm belief that herein lays the starting point for cultivating a biophilic and loving relationship with the earth. But the job of designing effective outdoor adventure training is far from over. Educators must recognize the potential to nurture the biophilia tendency with their programs and accept the role of outdoor adventure training in emotional change, relationship-building, and ultimately motivation for action. As referenced earlier, Orr (2004) and Sobel (1998) have argued humans will only save what they love, but love needs a place to plant its roots and grow.

At the same time, psychologists need to jump into the boat, so to speak. Valuing how nature is intertwined with our psyche needs to become a recognized not just in education, but also in psychological restoration and therapy. Surfing should be seen as a healthy stimulant for 
those individuals who need a boost in energy. Completing a wet exit from a kayak in a safe environment is an effective way to overcome deep fears, as Elijah's story demonstrates. It is one thing to promote the psychological benefits of being in nature from a university lab room, it is entirely another to don a salty, cold wetsuit in a chilly morning with Alex's words in your ears:

"If you're tired you jump in it. Gives you life back". 


\section{References}

Albrecht, G., Sartore, G. M., Connor, L., Higginbotham, N., Freeman, S., Kelly, B., Stain, H., Tonna, A., \& Pollard, G. (2007). Solastalgia. Australasian Psychiatry, 15(Supplement), S-95-S-98. Doi: 10.1080/10398560701701228

Albrecht, G. (2010). Solastalgia and the Creation of New Ways of Living. In S. Pilgrim, \& J. Pretty (Eds.), Nature and Culture: Rebuilding Lost Connections (pp. 217-234). London, UK: Earthscan Ltd.

Alderson, D. (2004). Sea-kayak around Vancouver Island [ebrary Reader version]. Calgary, AB: Rocky Mountain Books. Retrieved from the ebrary.

Abram, D. (2005). Depth ecology. In B. R. Taylor, \& J. Kaplan (Eds.), The Encyclopedia of Religion and Nature. Continuum. Retrieved from http://www.wildethics.org/essays/depth_ecology.html

Blaikie, A. (2008). The TREK program. Green Teacher, 83(Spring), 20-23.

Brewer, J. (2003). Phenomenology. In R. L. Miller, \& J. D. Brewer (Eds.), The A-Z of Social Research (pp. 228-231). doi: 10.4135/9780857020024

Creswell, J.W., \& Miller, D. W. (2000). Determining validity in qualitative inquiry. Theory Into Practice, 39(3), 124-130.

Csikszentmihalyi, M. (1997, Jul/Aug). Finding flow. Psychology Today, 30(4), 46-48+.

Eatough, V., \& Smith, J. (2006). 'I was like a wild, wild person': Understanding feelings of anger using interpretative phenomenological analysis. British Journal of Psychology, 97(4), 483-498.

Eriksson, P. \& Kovalainen, A. (2008). Qualitative methods in business research [eBook]. London, UK: Sage Publications Ltd. doi:10.4135/9780857028044

Giorgi, B. (2006). Can an empirical psychology be drawn from Husserl's phenomenology? In P. 
D. Ashworth, \& M. Cheung Chung (Eds.), Phenomenology and Psychological Science: Historical and Philosophical Perspectives (pp. 69-88). doi: 10.1007/978-0-387-337623_4

Golafshani, N. (2003). Understanding reliability and validity in qualitative research. The Qualitative Report, 8(4), 597-606. doi:10.1111/j.1475-4762.2010.00954.x

Hattie, J., Marsh, H. W., Neill, J. T., \& Richards, G. E. (1997). Adventure education and Outward Bound: Out-of-class experiences that make a lasting difference. Review of Educational Research, 67(1), 43-87

Hooksum Outdoor School. (2011). Retrieved December 10, 2011, from http://www.hooksumschool.com/

Kaplan, S. (1995). The restorative benefits of nature: Toward an integrative framework. Journal of Environmental Psychology, 15(3), 169-182. http://dx.doi.org/10.1016/02724944(95)90001-2

Kellert, S. R., \& Wilson, E. O. (Eds.). (1993). The biophilia hypothesis. Washington, DC: Island Press.

Kellert, S. R. (1993). The biological basis for human values in nature. In S. R. Kellert, \& E. O. Wilson (Eds.), The Biophilia Hypothesis (pp. 42-67). Washington, DC: Island Press.

Ketterer, W. P. (2011). Psychological change among Appalachian trail thru-hikers: An interpretive phenomenological analysis (Doctoral dissertation). Retrieved from ProQuest Dissertations and Theses (130).

Kidner, D. W. (2007). Depression and the natural world: towards a critical ecology of psychological distress. International Journal of Critical Psychology, 19(Spring), 123146.

Kolb, B. (2008). Marketing research. London: Sage Publications. doi:10.4135/9780857028013 
Kudryavtsev, A., Stedman, R. C., \& Krasny, M. E. (2012). Sense of place in environmental education. Environmental Education Research, 18(2), 229-250. Retrieved from http://dx.doi.org/10.1080/13504622.2011.609615

Lertzman, R. (2008). The myth of apathy. The Ecologist, (June), 16-17.

Louv, R. (2005). Last child in the woods: Saving our children from nature-deficit disorder. (1st ed.). Chapel Hill, NC: Algonquin Books of Chapel Hill.

Martin, B., Cashel, C., Wagstaff, M., \& Breunig, M. (2006). Outdoor leadership: Theory and practice. Champaign, IL: Human Kinetics.

Mayer, F. S., \& Frantz, C. M. (2004). The connectedness to nature scale: A measure of individuals' feeling in community with nature. Journal of Environmental Psychology, 24(4), 503-515. doi:10.1016/j.jenvp.2004.10.001

Merriam-Webster. (2012). Retrieved November 25, 2012 from http://www.merriamwebster.com/dictionary/psyche

McIntyre, N. (1999). Investigating adventure experiences: An experiential sampling approach. Scisco Conscientia, 1(1), 1-13.

Moran, D. (2000). Introduction to phenomenology. London, UK: Psychology Press.

Neill, J. T. (2008). Enhancing life effectiveness: The impacts of outdoor education programs. (Doctoral Dissertation). Retrieved from ProQuest Dissertations and Theses.

Orr, D. W. (2004). Earth in mind: on education, environment, and the human prospect. Washington, DC: Island Press.

Orr, D. W. (2011a). Love. In D. W. Orr (Eds.), Hope is an Imperative: The Essential David Orr (pp. 30-34). Washington, DC: Island Press. doi:10.5822/978-1-61091-017-0_4

Orr, D. W. (2011b). Ecological Literacy. In D. W. Orr (Eds.), Hope is an Imperative: The Essential David Orr (pp. 251-261). Washington, DC: Island Press. doi:10.5822/978-1- 
61091-017-0_4

Outward Bound Canada. (2012). Retrieved November 10, 2012, from

http://www.outwardbound.ca/

Outward Bound International. (2004). Retrieved December 10, 2011, from

http://www.outwardbound.net/about/history.html

Patterson, C. H. (1965). Phenomenological psychology. The Personnel and Guidance Journal, 43(10), 997-1005.

Payne, G. \& Payne, J. (2004). Key concepts in social research. Thousand Oaks, CA: Sage Publications. doi: 10.4135/9781849209397

Perkins, H. (2010). Measuring love and care for nature. Journal of Environmental Psychology, 30, 455- 463. doi:10.1016/j.jenvp.2010.05.004

Phenomenology Online. (2011). Retrieved December 10, 2011, from http://www.phenomenologyonline.com/

Rowley, T. (2010). Voices of change: Transformative learning in the TREK Outdoor Education Program. (Master's thesis). Retrieved from Library and Archives Canada.

Semken, S., \& Freemen, C. B. (2007). Sense of place in the practice and assessment of placebased science teaching. Science Education, 92(6), 1042-1057. doi:10.1002/sce.20279

Smith, D. B. (2010, January 31). Is there an ecological unconscious? The New York Times. Retrieved from http://www.nytimes.com/2010/01/31/magazine/31ecopsych-t.html

Smith, J. A., \& Eatough, V. (2007). Interpretative phenomenological analysis. In E. Lyons, \& A. Coyle (Eds.), Analysing Qualitative Data in Psychology (pp. 35-50). London: Sage Publications. doi:10.4135/9781446207536

Sobel, D. (1998). Beyond ecophobia. Yes!, (Education for Life, Winter).

Soulé, M. E. (1993). Biophilia: Unanswered questions. In S. R. Kellert, \& E. O. Wilson (Eds.), 
The Biophilia Hypothesis (pp. 441-455). Washington, D.C: Island Press.

Starks, H., \& Brown Trinidad, S. (2007). Choose your method: A comparison of phenomenology, discourse analysis, and grounded theory. Qualitative Health Research, 17(10), 1372 -1380. doi:10.1177/1049732307307031

Tashakorri, A., \& Teddlie, C. (2003). Handbook in mixed methods in social and behavioural research. Thousand Oaks, CA: Sage Publications.

Taylor, A. F., Kuo, F. E., \& Sullivan, W. C. (2001). Coping with ADD: The surprising connection to green play settings. Environment and Behavior, 33(1), 54-77. doi:10.1177/00139160121972864

TREK. (2011). Retrieved December 10, 2011 from http://www.trekoutdoorprogram.ca/

Wilson, E. O. (1993). Biophilia and the Conservation Ethic. In S. R. Kellert, \& E. O. Wilson (Eds.), The Biophilia Hypothesis (pp. 31-40). Washington, DC: Island Press. 


\section{Appendix A: Letter of Invitation to Participate in Research INVITATION TO PARTICIPATE IN RESEARCH PROJECT}

May 1, 2012

Dear Hooksum Outdoor School Participant,

My name is Meg Banavage and I will be participating in Hooksum's May program. I am also a graduate student at Royal Roads University. I would like to invite you to be a participant in my research project, which is a requirement for a Master's Degree in Environmental Education and Communication. My credentials with Royal Roads University can be established by contacting Dr. Richard Kool, Program Head, at

My research objective is to investigate expressions of love for Pacific coastal environments during outdoor adventure training. I will be attending Hooksum as a participant and researcher, and at any time will respect comments and thoughts you wish to be excluded from my research.

I will submit my final report to the University in partial fulfillment for a Masters of Arts. I may also share my findings in academic journals and professional gatherings in the environmental and psychology fields. You were chosen as a prospective participant as you are signed up for the May 2012 program.

Participation includes open-ended questions and surveys before, during, and in the final days of Hooksum's May program. I will be recording anonymous observations and there will also be individual interviews during the program. Questions will include open-ended questions and scaled responses pertaining to your relationship to the ocean, how you engage with coastal environments, and meaningful experiences you have had in coastal environments.

All documentation will be kept strictly confidential. I will not share or make available any personal information to an outside party not included in the research study. Information will be recorded in handwritten format, audio recorded, and, where appropriate, summarized, in anonymous format, in the body of the final report. At no time will any specific comments be attributed to any individual unless specific agreement has been obtained.

The research will be presented to Royal Roads University and a copy of the final report will be published and archived in the RRU Library, and can be made available to participants if requested.

Participants are able to join the study at any time. Those who agree to participate in the pre and/or final day program questions and surveys will have their name entered into a draw for a prize. Participants who agree to an additional in-depth interview during the program will be entered into a second draw for a prize. Prizes will be mailed out to winners mid July.

Please feel free to contact me at any time should you have additional questions regarding the project and its outcomes. There will not be a formal debriefing session after the interview, but I will be available throughout the duration of Hooksum's May program, and can be reached via email before the program begins and after its completion (see contact info below).

You are not required to participate in this project. If you choose to participate, you are free to withdraw at any time without prejudice. Similarly, if you choose not to participate your non-participation will remain in confidence.

If you would like to participate in my research project, please contact me at:

Meg Banavage,

Sincerely,

Meg Banavage, BA(Hons) 


\section{Appendix B: Research Consent Form}

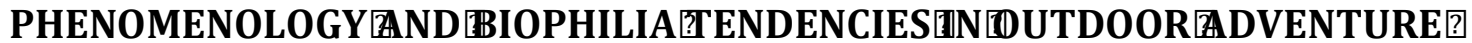 TRAINING: TRESERCHQONSENTTFORM?}

\section{?}

?

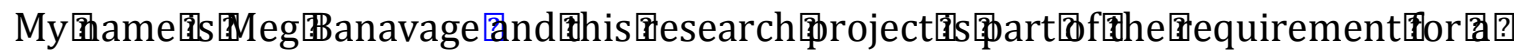

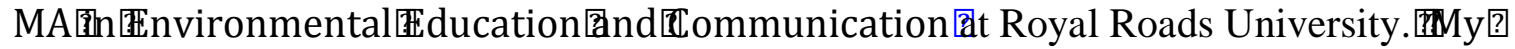

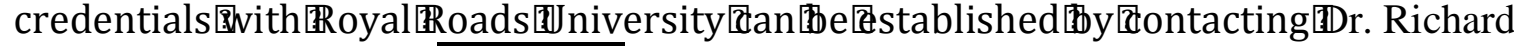

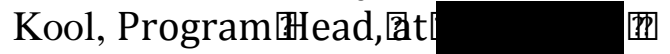

?

This团

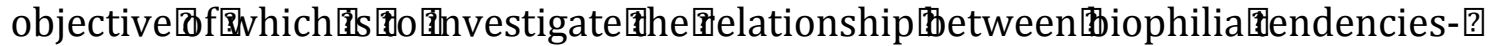
how

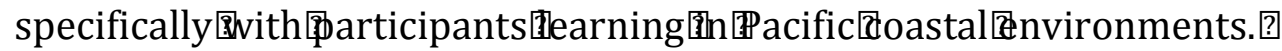
?

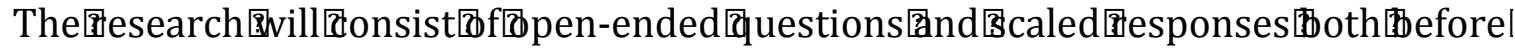
and during Hooksum's 8 -day国ay

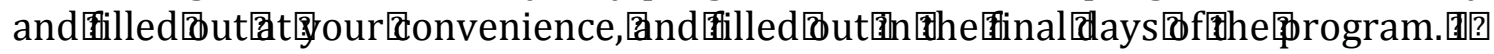

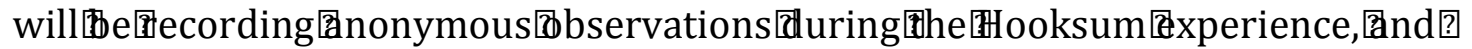

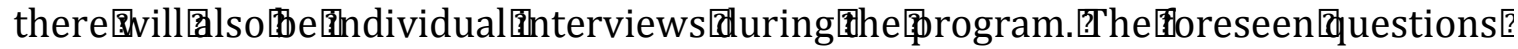

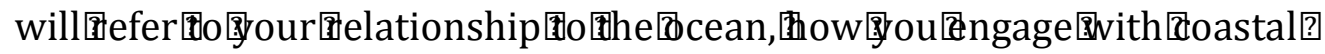

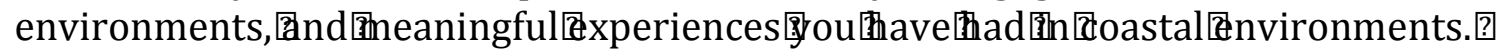

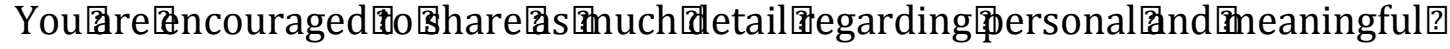

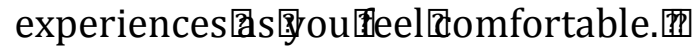

?

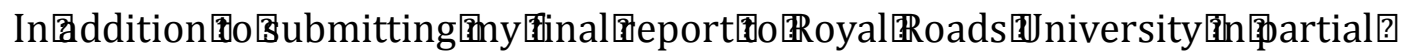

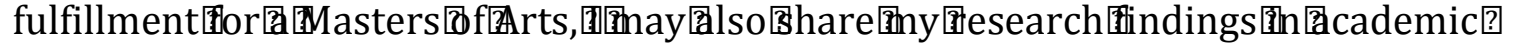

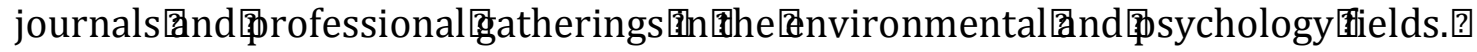

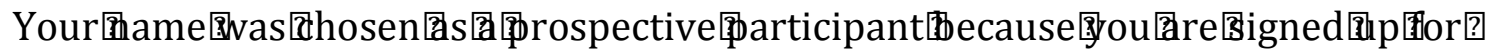

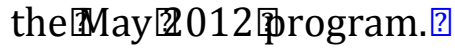

?

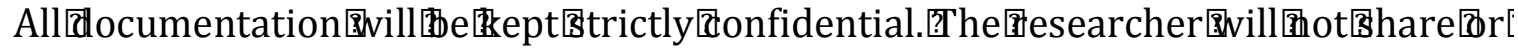

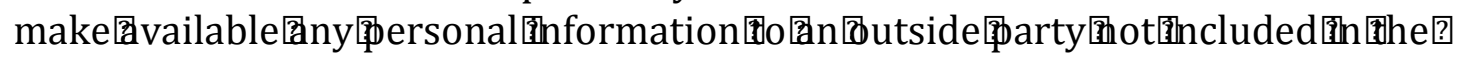

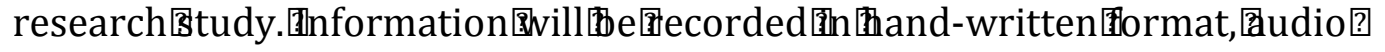

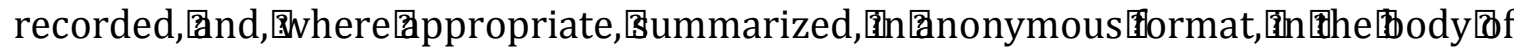

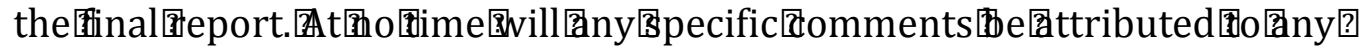

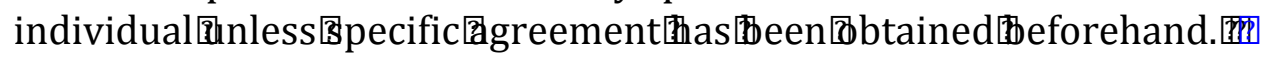
?

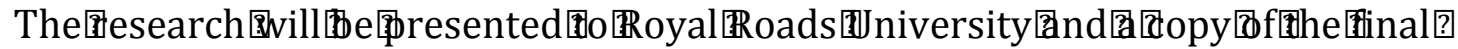

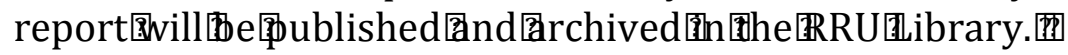

\section{?}

Participants国ho哥gree团o

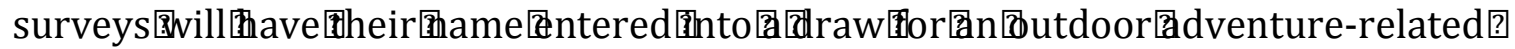

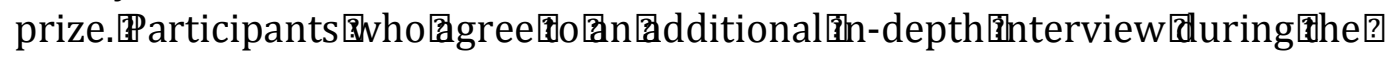
program 国ill

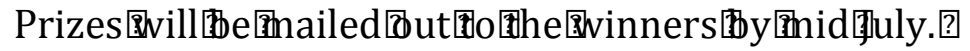




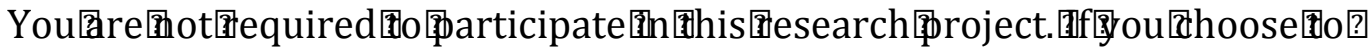

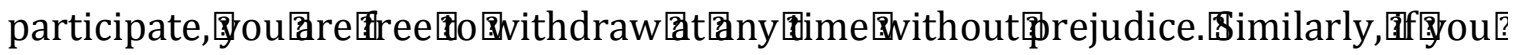

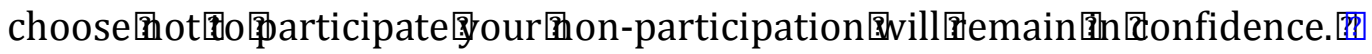
?

If

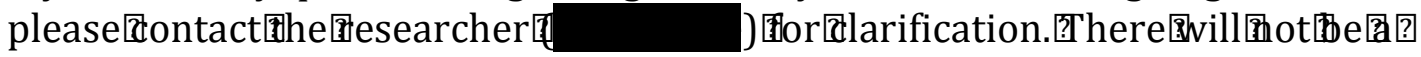
formal abriefing duration $\$$ f begins固nd固fter活tsompletion.?

?

?

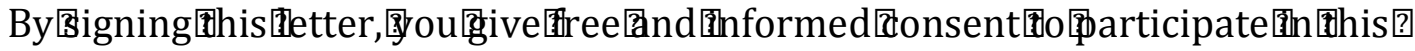
project. ?

回

Name (Please Print): ? ?

?

Signed:? ?

?

Date:? ?

? 


\section{Appendix C: Semi-Structured, In-Depth Interview Questions}

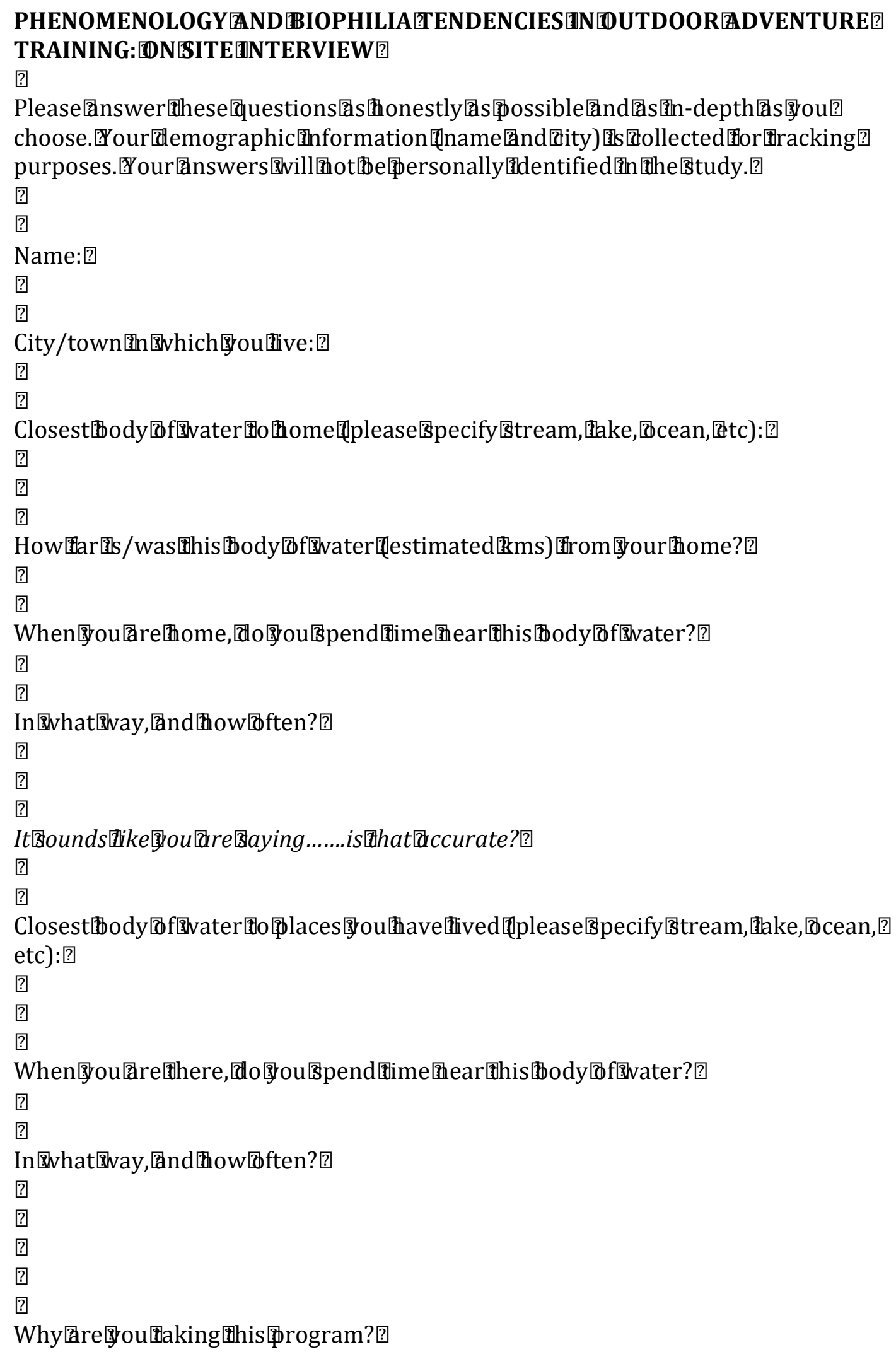


?

?

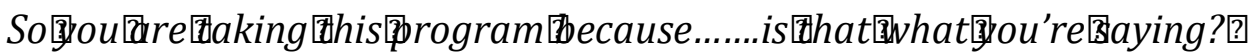

?

?

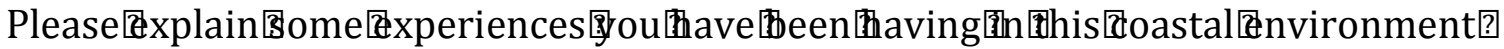
(at Hooksum).? ?

?

?

?

?

?

?

?

?

?

?

?

?

?

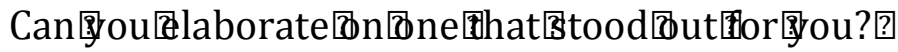

?

?

웅

?

?

?

?

?

?

?

?

?

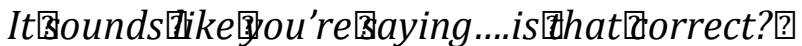

?

?

Are团here团ny团hings

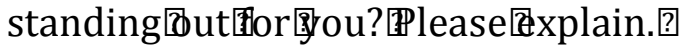

?

?

?

?

?

?

?

? 
?

?

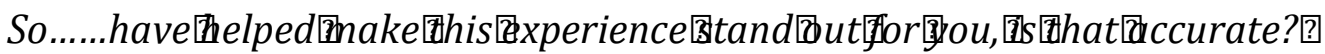

?

?

?

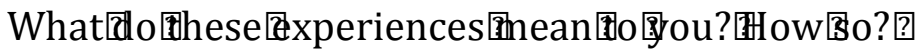

?

?

?

?

?

?

?

?

?

?

It

?

?

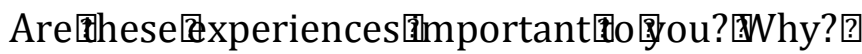

?

?

?

?

?

?

?

?

?

?

?

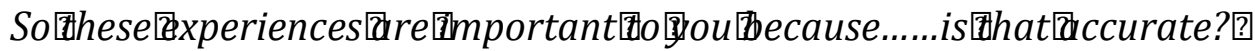

?

?

?

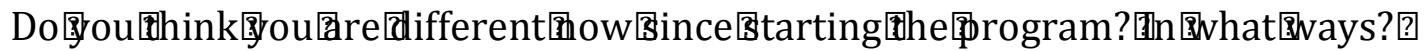

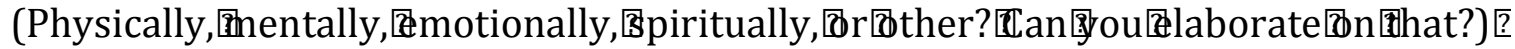
?

?

?

?

?

? 


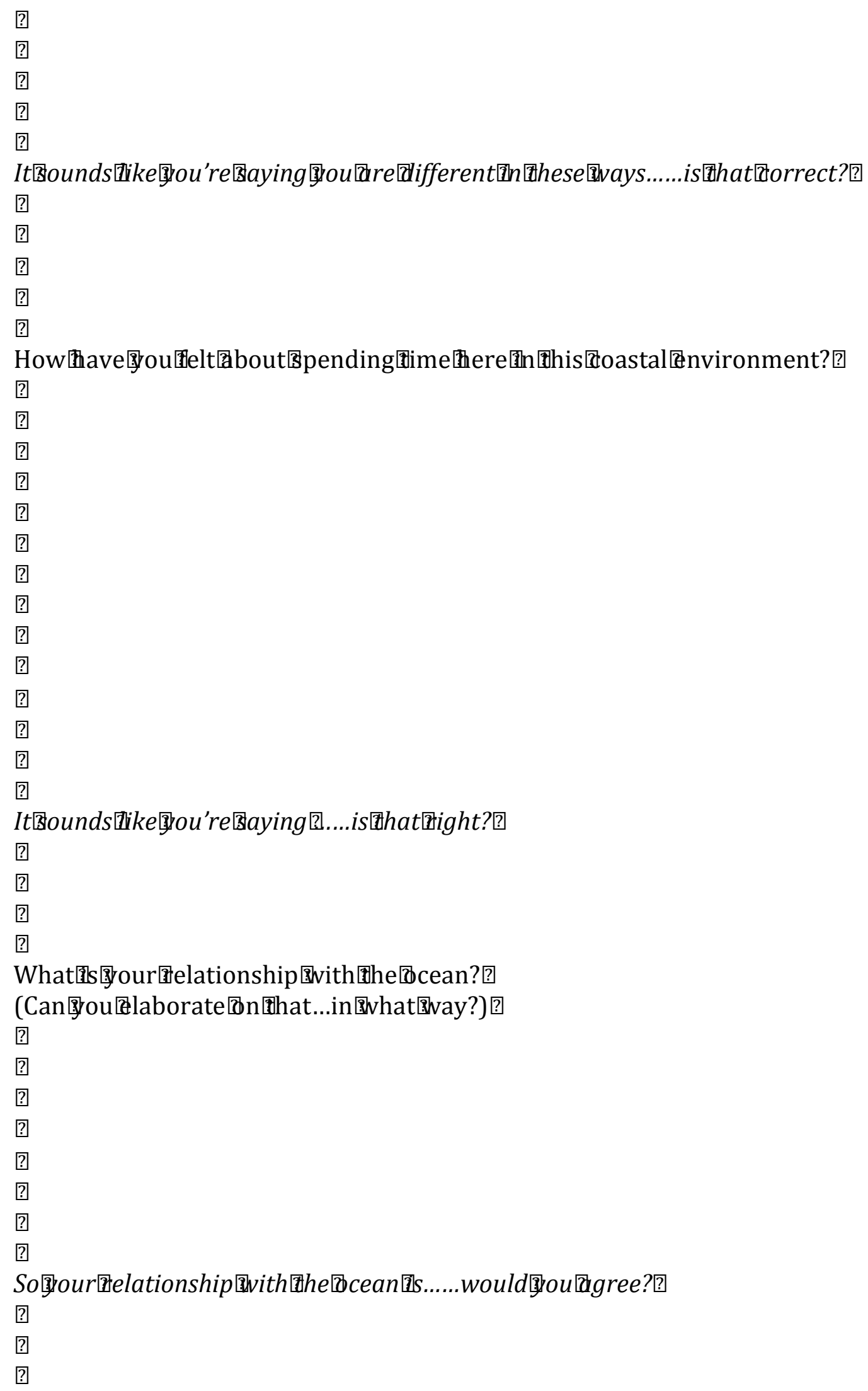




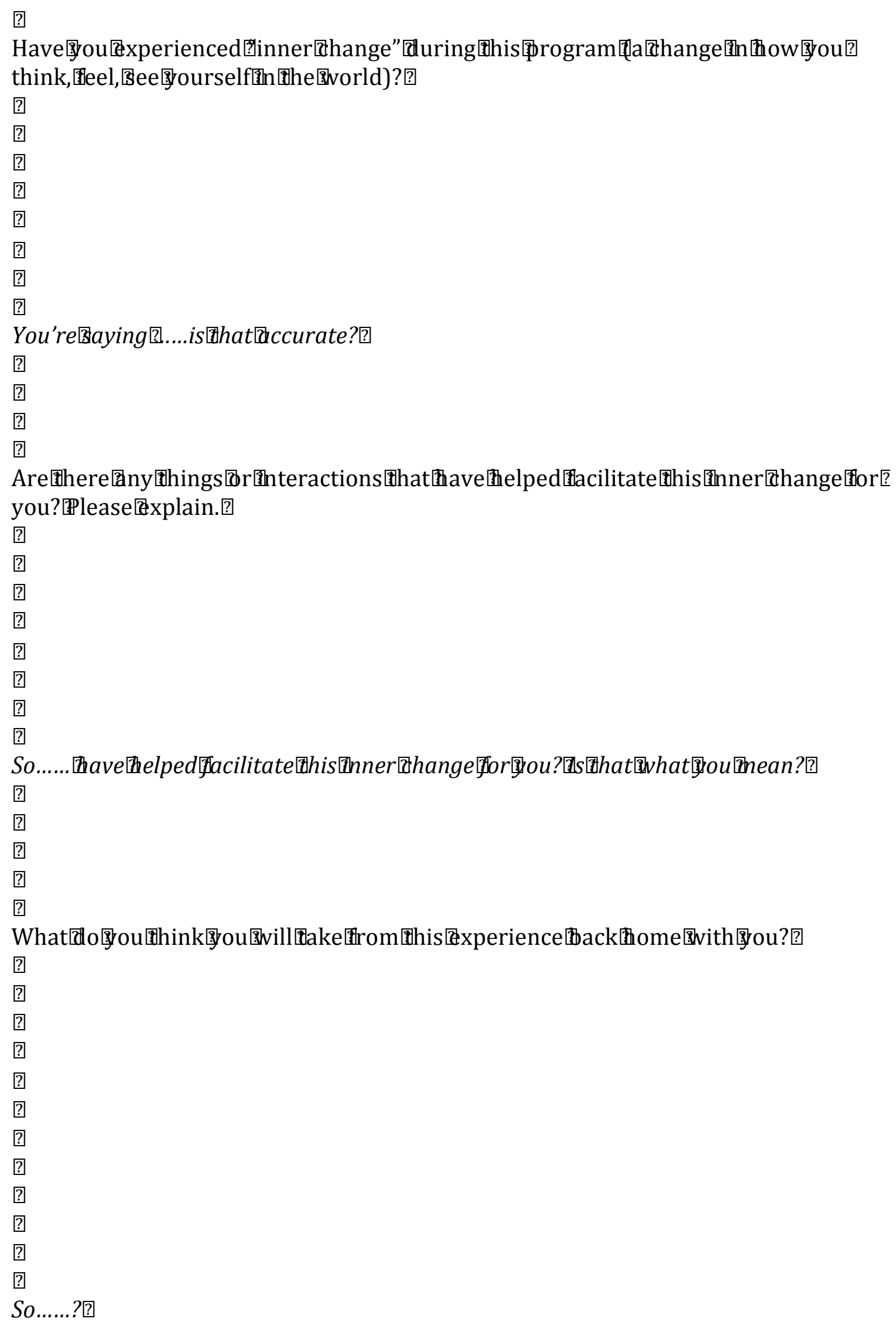




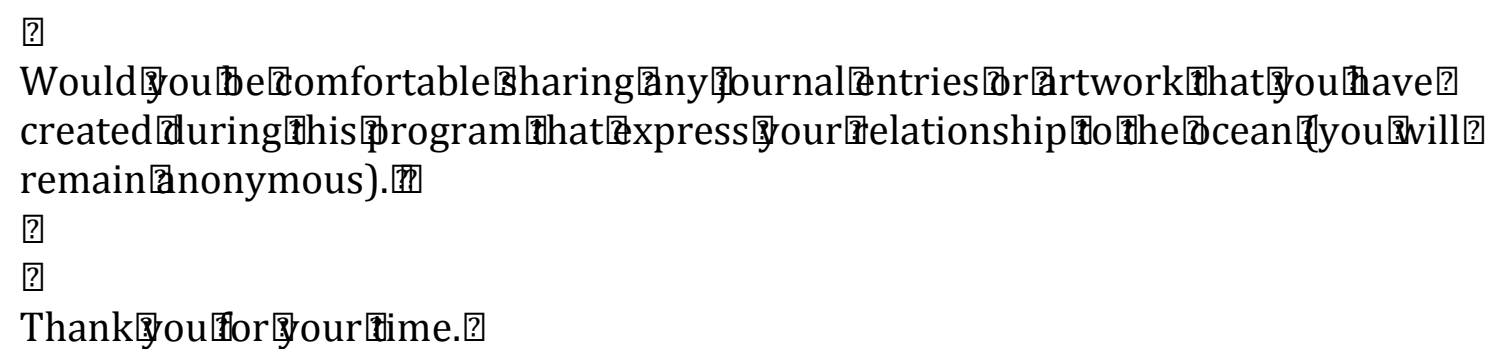

Thank国ou团or 国our团ime.? 


\section{Appendix D: Pre-Post Post Questionnaire}

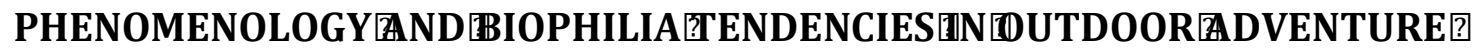 TRAINING: TPOSTPROGRAMQUESTIONS? \\ ?}

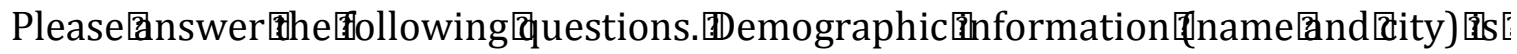

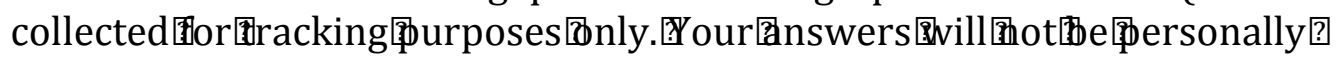

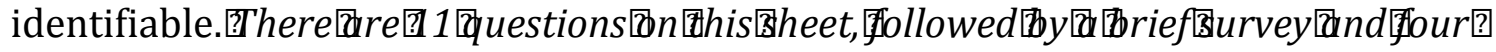
verbal币uestions. ?

?

1. Name:?

?

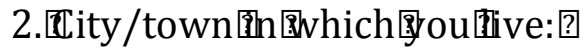

?

3. 囵losest

?

?

?

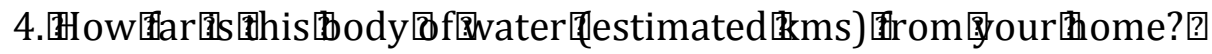

?

?

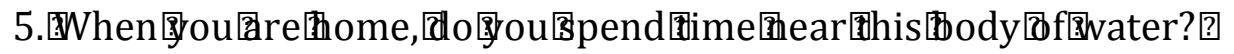

?

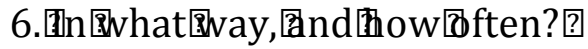

?

?

?

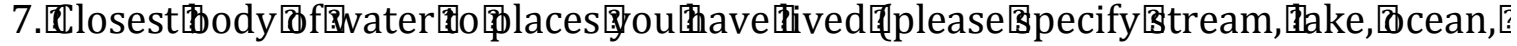
etc):?

?

?

?

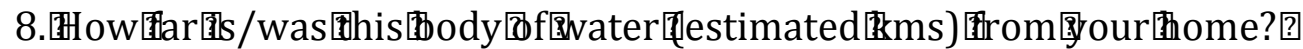

?

?

?

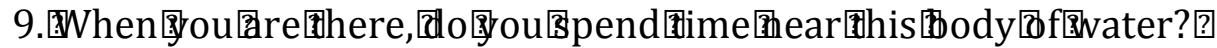

?

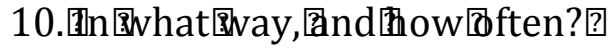

?

?

?

?

11. Why 司re gou taking this program??

? 


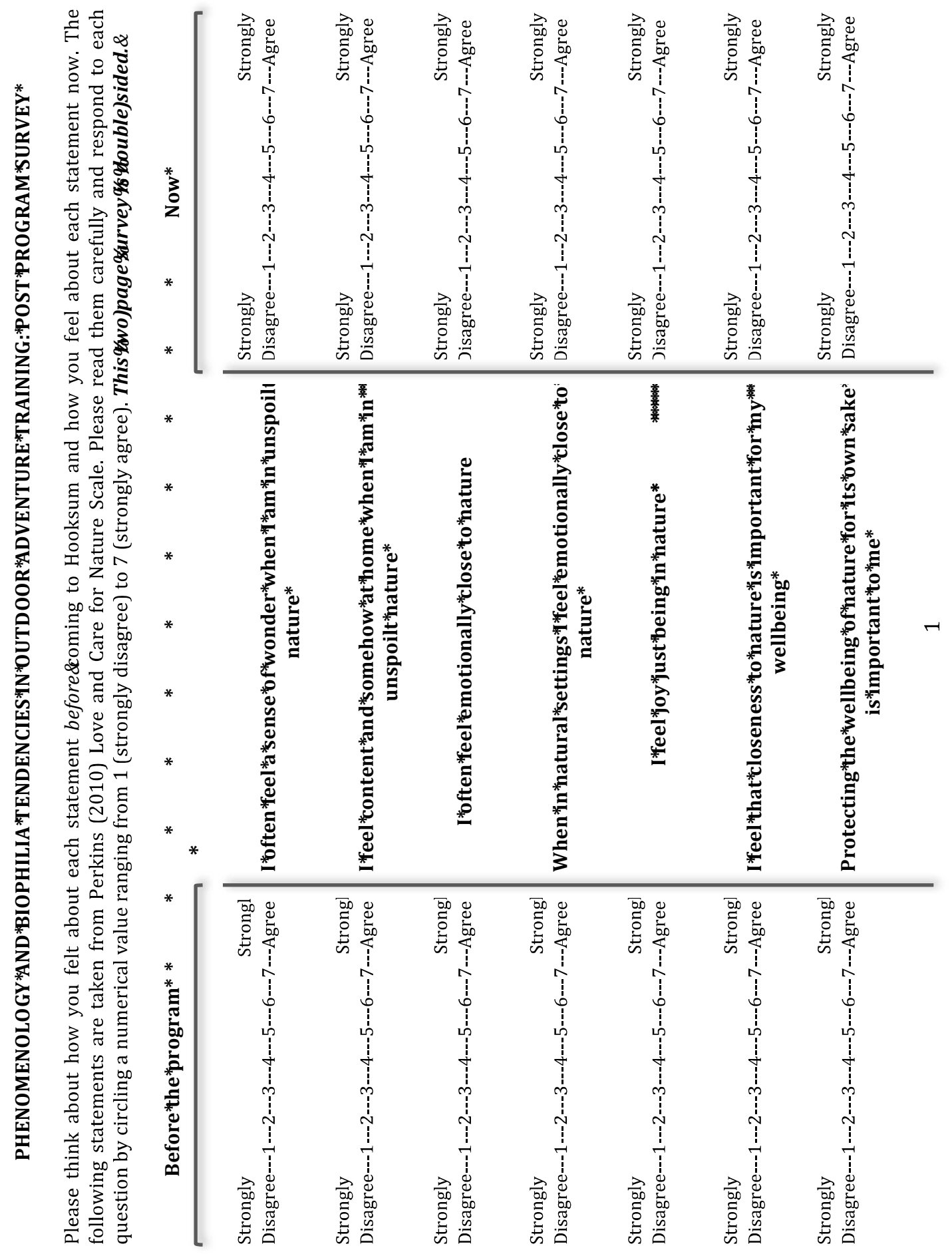




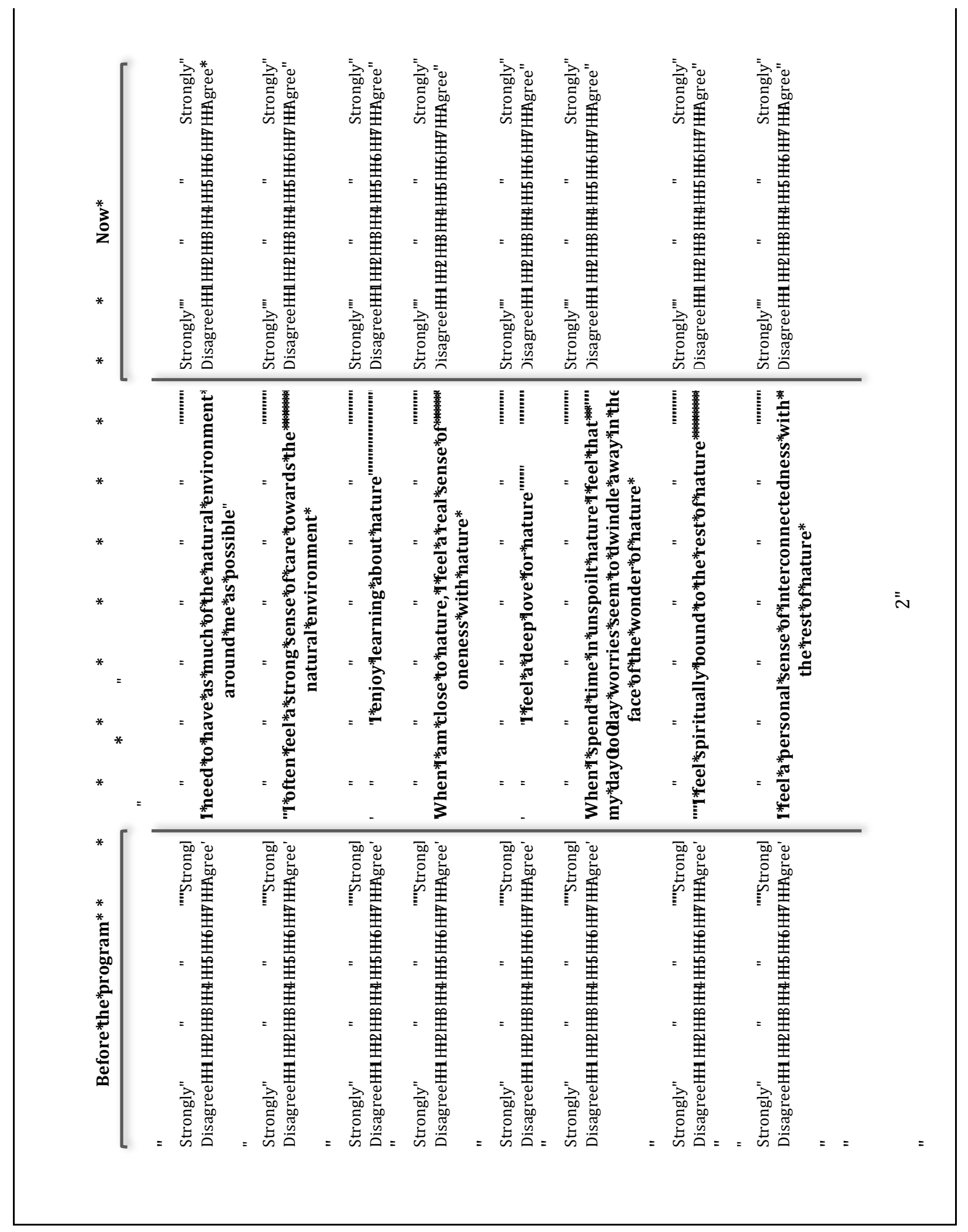




\section{Appendix E: Second Interviews}

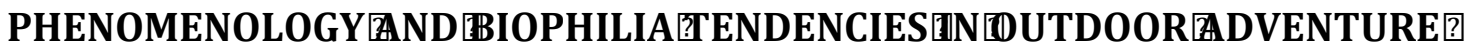

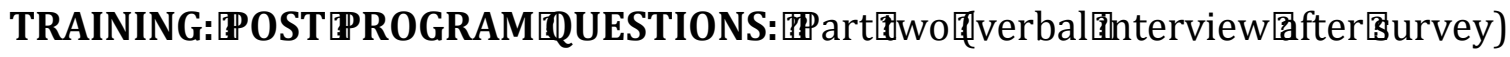
?

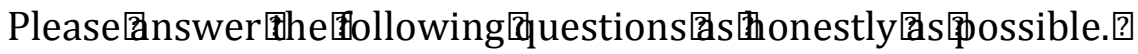

?

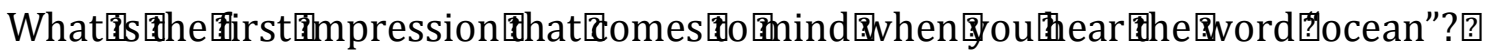
?

?

?

So.....correct??

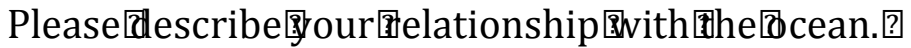

?

?

?

?

?

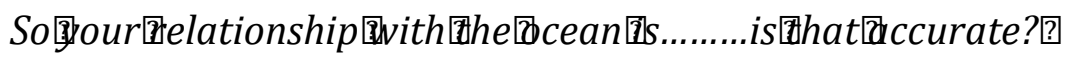

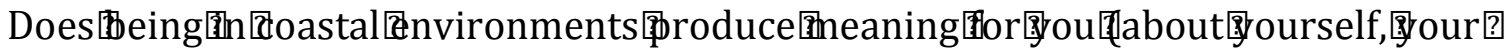

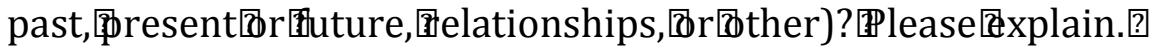

?

?

?

?

?

?

?

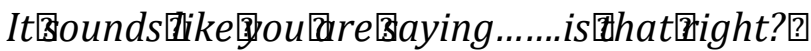

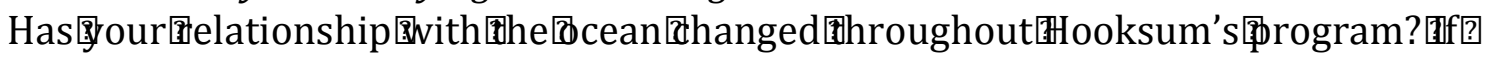

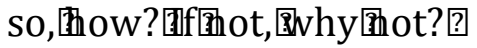

?

?

?

?

?

?

?

?

우

?

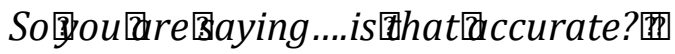

Thank国oufor gour time.?

?

? 


\section{Appendix F: Item Response Distributions of Participant Love and Care for Nature (LCN)}

\section{Scales}

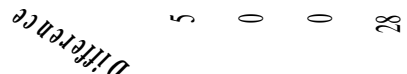

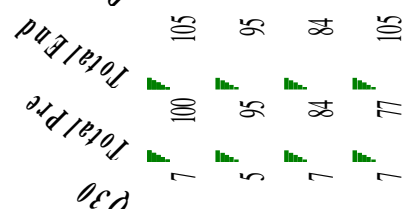

$$
\begin{aligned}
& \text { oid }- \text { n } \sim- \\
& \operatorname{sid}-\pi \text { in } \\
& \text { id }-6 \mathrm{~m} \text { - } \\
& \text { eyd in } T \text { - } \\
& \operatorname{sid}-T- \\
& \text { sid }-6+- \\
& \text { idj - } 0 \text { m - } \\
& \text { iोj }-+- \\
& \operatorname{lig}+-5 \\
& \text { aid }-6 \text { - } \\
& \text { oid }- \text { in } \\
& 8 / 0+6- \\
& \text { lo }-+- \\
& \text { e/d }+-+ \\
& \text { sid } 0 \text { in }- \text { + } \\
& \text { sid }- \text { in } \mathrm{C}+ \\
& \text { s/d }- \text { in }+ \\
& \text { id }-6 \mathrm{~m} \text { - } \\
& 1 / 0+\text { in }- \text { in } \\
& \text { old in }- \text { - } \\
& \text { ad }-6+5 \\
& \text { sd } 6 \text { o } \\
& \text { <d }+-+ \\
& \text { eg }-+- \text { - } \\
& \text { sj }-0-0 \\
& \text { so } 0-\text { in } 0 \\
& \text { sg }-+\infty+ \\
& \text { id }+r+ \\
& \text { id }-+n
\end{aligned}
$$

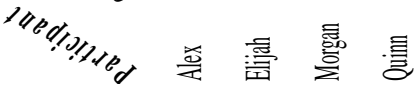

